Flow patterns and cleaning behaviour of stationary horizontal liquid jets impinging on angled walls

Tao Wang, John F. Davidson and D. Ian Wilson*

Submitted to

Food \& Bioproducts Processing

Special issue

Fouling \& Cleaning in Food Processing 2014

(C) TW, JFD \& DiW

September 2014

Revised Manuscript

*Corresponding author

Dr D.I.Wilson

Department of Chemical Engineering \& Biotechnology

University of Cambridge

New Museums Site

Pembroke Street

Cambridge

CB2 3RA, UK

E-mail diw11@cam.ac.uk

Tel

+44(0)1223334791 


\title{
Flow patterns and cleaning behaviour of horizontal liquid jets impinging on angled walls
}

\author{
Tao Wang, John F. Davidson and D. Ian Wilson* \\ Department of Chemical Engineering \& Biotechnology, University of Cambridge, New \\ Museums Site, Pembroke Street, Cambridge CB2 3RA, UK
}

*Corresponding author: diw11@cam.ac.uk

\section{ABSTRACT}

Liquid jets are widely used in cleaning operations in the food sector. Morison and Thorpe (2002) reported an experimental investigation of the flow patterns and cleaning behaviour of horizontal jets impinging on vertical walls. The Wilson et al. (2012) model, which described Morison and Thorpe's flow pattern data well, is extended to describe the flow pattern generated by a liquid jet, approaching a surface at a given angle to the horizontal, impinging on a plate inclined at a known angle to the vertical. The results are compared with experimental data collected for horizontal water jets impinging on inclined Perspex and glass plates. Tests employed nozzle diameters of 1,2 and $3 \mathrm{~mm}$ at room temperature, using flow rates of 0.78-2.23 $\mathrm{g} \mathrm{s}^{-1}$; 3.7-9.9 $\mathrm{g} \mathrm{s}^{-1}$; and 7.1-17.3 $\mathrm{g} \mathrm{s}^{-1}\left(0.025-0.062 \mathrm{~m}^{3} \mathrm{~h}^{-1}\right)$ respectively. These are lower than industrial cleaning flow rates. The angle at which the horizontal jet impinged on the plate was varied from $30^{\circ}$ to $120^{\circ}$. Two important dimensions are evaluated: (i) the width of the fast moving radial flow zone on the plate (the region bounded by the film jump, the feature similar to a hydraulic jump) at the plane of impingement; (ii) the distance on the plate to which the radial flow zone extends above the point of impingement. Both are described reasonably well by the model. Empirical relationships are reported for the width of the wetted region at the level of impingement, and the maximum width of the draining film. A short study of cleaning of layers of washable paint on glass, similar to the tests reported by Morison and Thorpe, show that the cleaning model recently developed by Wilson et al. (2014) gives a good description of the initial cleaning of such layers using an impinging stationary coherent water jet.

Key words: cleaning, impinging jet, model, hydraulic jump 


\section{INTRODUCTION}

Liquid jets are widely used to remove surface soiling or fouling layers when cleaning process equipment. Their use for cleaning the internals of tanks and other vessels is increasing in the food, pharmaceutical and fine chemicals sectors as they offer several advantages over simple 'fill and soak' strategies in employing smaller volumes of liquid and generally requiring less time (Jensen, 2011). The performance of jet cleaning systems such as spray balls, solid-stream nozzles, jet heads and rotating spray arms (e.g. in dishwashers) depends strongly on the wetting pattern of the liquid on the wall. For cases where cleaning arises primarily from the chemical or detergent action of the liquid, it is important to be able to predict whether the design will achieve complete coverage of the target area with liquid. For cases where cleaning also requires a high shear stress, knowledge of the shear stress distribution is required. Both instances require a working knowledge of the flow patterns created by the liquid jet when it impinges on the wall.

When a liquid jet impinges on the wall, it can rebound, giving splashback (e.g. Lienhard et al., 1992), or spread radially away from the point of impingement as a fast moving film. At some distance from the point of impingement the liquid slows down and a jump is formed, where the film depth increases and gravity dominates the flow pattern. Whereas the case of a liquid jet impinging vertically downwards on a horizontal plate, giving a hydraulic jump, has been studied extensively in the fluid mechanics literature (e.g. Watson, 1964), the case of a liquid jet impinging on a vertical wall has received relatively little attention. Morison and Thorpe (2002) reported an experimental investigation of the flow pattern created by a horizontal jet from a spray ball impinging on vertical walls. Wilson et al. (2012) subsequently developed a model which predicted Morison and Thorpe's data sets well.

In this paper, the flow pattern and cleaning behaviour of impinging jets such as those generated by spray balls, albeit at flow rates below the lower end of the range employed in industry, was investigated by considering a single coherent jet impinging on clean, inclined plates. The flow rates ( $1 \mathrm{~mm}$ nozzle, $0.7-2.4 \mathrm{~g} \mathrm{~s}^{-1} ; 2 \mathrm{~mm}$ nozzle, $3-11 \mathrm{~g} \mathrm{~s}^{-1} ; 3 \mathrm{~mm}$ nozzle, $7-17$ $\mathrm{g} \mathrm{s}^{-1}$ ) are similar to those employed by Wang et al. (2013a), who studied stationary jets impinging on vertical walls at different angles of inclination. Industrial static spray balls are typically operated at 2 barg, giving flow rates of $16 \mathrm{~g} \mathrm{~s}^{-1}\left(0.056 \mathrm{~m}^{3} \mathrm{~h}^{-1}\right)$ and $141 \mathrm{~g} \mathrm{~s}^{-1}(0.51$ $\mathrm{m}^{3} \mathrm{~h}^{-1}$ ) for 1 and $3 \mathrm{~mm}$ diameter holes, respectively. The purpose of this paper is to develop a 
model to describe the flow behaviour. Its application at industrial flow rates will require larger apparatuses, such as that described by Wilson et al. (2014), or even larger (for surfaces inclined at acute angles to the flow.

The Wang et al. (2013a) model is extended to include the case where the jet impinges on inclined surfaces (i.e. the surface is not vertical). The model is written for the general case of jets inclined at an arbitrary angle but experiments were only performed using horizontal jets.

A short study of the cleaning performance of these water jets is presented for a stationary coherent jet impinging horizontally on a painted vertical glass wall, mimicking that reported by Morison and Thorpe. The removal of the paint layer by adhesive detachment, i.e. leaving the substrate almost clean, is successfully described by the Wilson et al. (2014) cleaning model.

\section{MATERIALS AND METHODS}

\section{Apparatus}

Experiments employed the apparatus reported in detail in Wang et al. (2103b). Water flowed under gravity from an elevated $20 \mathrm{~L}$ holding tank through a control valve and pressure gauge before discharging through the nozzle. The stainless steel piping had an i.d. of $4 \mathrm{~mm}$, with removable nozzles of throat diameter $d_{\mathrm{N}}=1 \mathrm{~mm}, 2 \mathrm{~mm}$ or $3 \mathrm{~mm}$. The internal convergence angles, measured from the nozzle centre-line to the conical surface, were $45^{\circ}, 56^{\circ}$ and $71^{\circ}$, respectively. The angle of inclination of the nozzle to the horizontal was set by a pivot. The pressure drop across the nozzle was used to monitor the flow rate, using the coefficients of discharge reported in Wang et al. (2013a). The $0.5 \mathrm{~m}$ gravity head used in these tests gave mass flow rates, $\dot{m}$, of $0.78-2.23 \mathrm{~g} \mathrm{~s}^{-1}$ for $d_{\mathrm{N}}=1 \mathrm{~mm} ; 3.7-9.9 \mathrm{~g} \mathrm{~s}^{-1}$ for $d_{\mathrm{N}}=2 \mathrm{~mm}$, and 7.1$17.3 \mathrm{~g} \mathrm{~s}^{-1}$ for $d_{\mathrm{N}}=3 \mathrm{~mm}$. The jet Reynolds number, $R e_{\text {jet }}$, based on jet diameter, ranged from $500-3,200$ at $20 \pm 2^{\circ} \mathrm{C}$.

The target plates were transparent, with dimensions $300 \mathrm{~mm} \times 330 \mathrm{~mm} \times 5 \mathrm{~mm}$ (thickness), made from Perspex (polymethylmethacrylate), and float glass (borosilicate glass). The plate was positioned approximately $30 \mathrm{~mm}$ away from the nozzle and could be rotated about a horizontal axis so that its plane lay at angle from $0^{\circ}$ to $\pm 60^{\circ}$ to the vertical. The flow pattern created by the jet was photographed using a Nikon D5000 12 megapixel camera located 
behind the target. Transparent ruled tape was attached to the dry side of the target to allow distances to be extracted accurately from the photographs.

The tests reported here used local tap water at a temperature of $20^{\circ} \mathrm{C} \pm 2{ }^{\circ} \mathrm{C}$. This water is hard, with composition $122 \mathrm{mg} \mathrm{L}^{-1}$ as $\mathrm{Ca}^{2+}$ and $322 \mathrm{mg} \mathrm{L}^{-1}$ as $\mathrm{CaCO}_{3}(\mathrm{Cambridge}$ Water Company, 2013). The advancing contact angle, $\beta$, for water was measured at room temperature using a Krüss DSA 100S drop shape analyser, starting with a $5 \mu \mathrm{L}$ drop and increasing the volume to 20-50 $\mu \mathrm{L}$ until $\beta$ was constant. This gave $\beta=70^{\circ} \pm 10^{\circ}$ on the glass and $\beta=90^{\circ} \pm 10^{\circ}$ on the Perspex.

The selection criteria proposed by Stenby et al. (2011) were used to select model fouling layers, namely: opaque when wet (no foaming); cheap; safe to dispose to drain; ease of application with approximately uniform thickness; and lack of cracking or peeling when dry. Blue washable liquid tempera paint (Reeves, UK) on glass was used for these tests. On Perspex the paint peeled off readily when dry so only glass substrates were used. $20 \pm 5 \mathrm{~g}$ paint was applied evenly across the glass using a paint brush. Drying was quite rapid at room conditions $\left(20 \pm 2{ }^{\circ} \mathrm{C}\right.$, relative humidity $\left.55 \%-70 \%\right)$, becoming dry to touch after $3 \mathrm{~h}$. After 4 $\mathrm{h}$ the average paint layer thickness was $60 \pm 10 \mu \mathrm{m}$ (measured by micrometer) accompanied by a mass loss of $75-80 \%$. Some striations were generated by the brushing application. Residual paint was removed by a combination of soap in warm reverse osmosis (RO) water, followed by a wash of $99.5 \%$ ACS reagent grade ethanol in de-ionised water (ratio 3:7 v/v), and finally with a wash of $\geq 99.5 \mathrm{wt} \%$ ACS reagent grade acetone.

\section{MODELLING}

On a vertical wall, the liquid from the jet flows radially outwards from the point of impingement until a feature resembling a hydraulic jump occurs, which is here termed the film jump. Knowledge of the location of the film jump is important as this is the boundary of the radial flow zone (RFZ) wherein the highest shear stresses are generated. A circular jet forms an elliptical zone on impact if the jet impinges obliquely on a vertical wall or a horizontal jets impinges on inclined surface. Wang et al. (2013a) developed a model for the size of the $R F Z$ for jets impinging obliquely on a vertical surface by combining the Wilson $e t$ al. (2012) model with the Kate et al. (2007) model for hydraulic jumps created by inclined 
jets. The Wang et al. (2013a) model is extended here to describe oblique jets impinging on a non-vertical plate.

In Figure 1, the angle of inclination of the plate to the horizontal is $\lambda . \lambda$ as shown is $60^{\circ}$ and is $90^{\circ}$ if the plate is vertical. The angle of the jet to the horizontal is $\alpha: \alpha$ is defined as negative in the anti-clockwise direction, as shown in Figure 1(a). The angle at which the jet strikes the plate, $\phi$, is now given by $\phi=\lambda-\alpha$. The Wang et al. (2013a) model describes the flow in the RFZ and considers the effect of gravity on the flow along a streamline inclined at azimuthal angle $\theta$ along the plate (see Figure 1(b)). The evolution of the local mean velocity in the film, $U$, in the $R F Z$ is given by

$$
\frac{d U}{d r}=-10 \frac{v}{U_{o}^{2} r_{e}^{4} \sin ^{2} \phi} r^{2} U^{2}-\frac{5}{6} \frac{g \cos \theta}{U} \sin \lambda
$$

where $v$ is the kinematic viscosity and $g \sin \lambda$ is the component of gravitational acceleration acting along the wall. Figure 1 and Equation (1) are written for the general case of a jet inclined to the horizontal striking a non-vertical wall. Experimental results are reported for the case of a horizontal jet, where $\alpha=0$.

When an inclined jet of cylindrical cross-section strikes a flat wall it forms an elliptical impingement region (see Kate et al., 2007). Around the point of impingement, conservation of mass and kinetic energy gives rise to an elliptical region in which the mean velocity is the same as the jet velocity, $U_{\mathrm{o}}$. This follows from Bernoulli's theorem and the assumption of uniform velocity across the liquid film: because the pressure is constant, the surface velocity must be constant, at $U_{\mathrm{o}}$. The small black 'impingement ellipse is shown in Figure 1(b): $r_{e}$ is its polar radius at azimuthal angle $\theta, r_{e}$ varies with $\theta$, the variation depending on $\phi$.

The velocity $U$ at distance $r\left(r>r_{\mathrm{e}}\right)$ is obtained by integrating Equation [1] subject to the boundary conditions:

(i) $\quad U=U_{\mathrm{o}}$ (jet velocity) at $r=r_{\mathrm{e}} ; r_{\mathrm{e}}=f(\theta)$.

(ii) At $r=R_{\theta}$, where the film jump is reached, the outward flow of momentum is matched by the surface tension in the film (see Wilson et al., 2012). A momentum balance gives 


$$
U_{R \theta}=\frac{5}{3} \frac{\gamma(1-\cos \beta)}{U_{o} \rho r_{e}^{2} \sin \phi} R_{\theta}
$$

where $\gamma$ is the liquid-vapour surface tension. $R_{\theta}$ is found by integrating Equation [1] until $U(r)$ satisfies Equation [2].

Two values of $R_{\theta}$ are of particular interest. The half-width of the $R F Z$ at the midplane, where $\theta=$ $\pi / 2$, is denoted $R$ (see Figure $1(b)$ ). The half-width of the wetted region, including the corona or rope at this level, is labelled $R_{\mathrm{c}}$. The term rope is used subsequently to describe the flow around the RFZ. The maximum in the height of the film jump, at $\theta=0$, is labelled $Z_{\mathrm{r}}$ and is strongly affected by the angle of impingement. The maximum height of the wetted region, also at $\theta=0$, is labelled $Z_{\mathrm{t}}$. Strictly speaking, the above model only describes $R F Z$ dimensions above the midplane, as the termination condition (Equation [2]) in the falling film below the midplane differs from that above. Calculations of $R$ and $Z_{\mathrm{r}}$ were performed using Matlab ${ }^{\mathrm{TM}}$ on a desktop PC.

\section{RESULTS AND DISCUSSION}

\section{Radial flow zone: horizontal jet impinging on an inclined wall}

Table 1 is a summary of the flow patterns observed in the experiments. The photographs in Figure 2 are all cases of rivulet flow, where the falling film narrowed relatively quickly downstream and formed a node, similar to the braiding phenomenon studied by Mertens et al. (2005). In cases of multi-rivulet flow, two or more rivulets were formed and these meandered randomly down the plate. In gravity flow, the falling film created by the impinging jet remained wide some distance below the point of impingement. This regime is desirable for cleaning, as the wetted region is larger. Increasing the mass flow rate promoted the transition from rivulet to gravity flow, as reported previously by Wang et al. (2013a). Dry patch formation was sometimes observed in gravity flow, where the falling film split to form two strands either side of the vertical line of symmetry drawn through the point of impingement.

The photographs in Figure 2 show that the $R F Z$ became more elliptical as $\lambda$ differs from $90^{\circ}$. A stable film jump was observed with the horizontal jet impinging on inclined surfaces for $\lambda<90^{\circ}$, while dry patch or multi-rivulet behaviour was sometimes observed for $\lambda>90^{\circ}$ at higher flow rates. With a horizontal impinging jet the maximum film jump width became wider as $\lambda$ increased for a given flow rate. This behaviour is similar to that observed for 
oblique jets impinging on vertical surfaces (Wang et al., 2013a), where the $R F Z$ became more elliptical as $\phi$ differed from $90^{\circ}$. Similar behaviour was observed for other nozzles on both Perspex and glass. At the flow rates employed in these tests losses due to splashback on impact were negligible.

Figure 3 compares the dimensions of the $R F Z$ for the $d_{\mathrm{N}}=2 \mathrm{~mm}$ nozzle measured at low flow rates with the model predictions (Equations [1] and [2]) for three angles of plate inclination on both glass and Perspex. The substrate nature, i.e. the contact angle, affects the dimensions noticeably, as expected from Equation [2]. Similar trends were observed with the 1 and $3 \mathrm{~mm}$ nozzles. Wang et al. (2013a) found that the substrate nature was not so influential at higher flow rates; however, significantly larger plates would be required to study high flow rates for some of the $\lambda$ values employed here. The data are plotted as $2 R$ and $Z_{\mathrm{r}}$ in Figure 3 in order to allow the two lengths to be distinguished. An alternative format would be to plot the ratio $Z_{\mathrm{r}} / R$, which is presented in the Appendix.

Figure $3(a)$ shows that the model is able to predict both $2 R$ and $Z_{\mathrm{r}}$ with reasonable accuracy for horizontal jets at $\lambda=45^{\circ}$. The agreement was less good in predicting $Z_{\mathrm{r}}$ if gravity was neglected: all the loci in these plots include the gravity term. It should be noted that gravity does not affect $R$ much in these tests as $\theta=90^{\circ}$. The increase in $Z_{\mathrm{r}}$ with increasing flow rate is less strong than the increase in the width of the film jump, $2 R$, indicating that the film jump becomes more elliptical at higher flow rates. This behaviour is similar to that observed with oblique jets impinging on a vertical wall (Wang et al., 2013b). There is also good agreement for impingement on a more vertical surface $\left(\lambda=60^{\circ}\right)$ in Figure $3(b)$. Both $2 R$ and $Z_{\mathrm{r}}$ are noticeably larger than the values in Figure 3(a), which is due to a larger fraction of the total flow being directed above the impingement point.

Figure 3(c) does not show such good agreement for $\lambda=120^{\circ}$. When $\lambda>90^{\circ}, Z_{\mathrm{r}}>R$ because more liquid is directed upwards than sideways. Wang et al. (2013a) also found that their oblique jet model underpredicted $2 R$ and overpredicted $Z_{\mathrm{r}}$ for larger angles of incidence. The model presented here also underpredicts $2 R$. This is likely be due to the effect of gravity on the streamlines as the liquid flows away from the impingement point (they are assumed to remain radial here). The (albeit slight) overprediction of $Z_{r}$ for $\lambda=120^{\circ}$ is related to the large amount of liquid directed upwards and forming a rope around the RFZ. Liquid falling 
downward from the rope overlaps the edge of the $R F Z$ and reduces the measured $Z_{\mathrm{r}}$. In conclusion, the inclined surface model provides a conservative estimate of the $R F Z$ dimensions, which allows the size of the wetted area and the area subjected to high shear stress, with associated high cleaning rates, to be estimated.

The above results confirm that the angle of incidence has a large effect on the shape of the $R F Z$, with large angles of incidence giving rise to a film climbing noticeably up the plate before falling down in a wider film. This is evident from the ratio of $Z_{\mathrm{r}}$ to $R$ : Appendix 1 demonstrates this by presenting the data from Figure 3 in this format.

\section{Relating $R_{\mathrm{c}}$ and $R_{\max }$ to $R$}

The dimensions of the falling film are related to the width of the film at the mid-plane, $R_{\mathrm{c}}$, see Figure $1(b)$. A priori prediction of $R_{\mathrm{c}}$ requires mastery of the fluid dynamics of the film in the $R F Z$ and the circumferential flow in the rope region, which is beyond the scope of the momentum balances employed here. Numerical simulations of the free surfaces based on volume of fluid approaches, such as those described by Gunjal et al. (2005), offer promise in this area but even these will have to address the challenges posed by moving contact lines, where the physics is complex (see Blake, 2006). The approach employed here is to report empirical correlations between the observed parameters, $R_{\mathrm{c}}$ and $R_{\max }$ (see Figure $1(b)$ ), and $R$ (which can be predicted with reasonable confidence).

Wilson et al. (2012) and Wang et al. (2013b) reported that the relationship between $R_{c}$ and $R$ for horizontal jets impinging on vertical surfaces changed from $(i) R_{c}=2 R$, observed for water with a $1 \mathrm{~mm}$ diameter nozzle at low flow rates (less than $10 \mathrm{~g} \mathrm{~s}^{-1}, R e_{\text {jet }}<5,000$ ), to (ii) $R_{c}$ $=4 R / 3$ for a $3 \mathrm{~mm}$ nozzle at higher flow rates $\left(>13 \mathrm{~g} \mathrm{~s}^{-1}, R e_{\text {jet }}>13,000\right)$. Figure $4(a)$ shows the results for horizontal jets impinging on inclined glass at $20^{\circ} \mathrm{C}$ with a $1 \mathrm{~mm}$ nozzle at flow rates similar to those reported in Wang et al. (2013b) $\left(0.7 \mathrm{~g} \mathrm{~s}^{-1}\right.$ to $\left.2.3 \mathrm{~g} \mathrm{~s}^{-1}\right)$. The same behaviour is seen here, with $R_{c} \approx 2 R$, except that $R_{c}$ is slightly greater than $2 R$ when $\lambda=120^{\circ}$. This is attributed to the large amount of water passing above the mid-plane and entering the rope, then draining downwards. Figure $4(b)$ shows that similar behaviour was observed on glass for the $d_{\mathrm{N}}=3 \mathrm{~mm}$ at higher flow rates. The same trends were observed with the $d_{\mathrm{N}}=2$ mm nozzle, and Figure 5 compares the results for glass and Perspex with this nozzle. The empirical result, that $R_{c} \approx 2 R$, offers a conservative estimate of $R_{c}$ for $\lambda \leq 90^{\circ}$. Larger angles are likely to be found higher up on tank walls, e.g. above a spray nozzle unit, or the tank roof. 
Relating $R_{\max }$ to $R$

Whereas knowledge of the film width at the plane of impingement is sufficient to estimate the falling film width for horizontal jets, for non-horizontal jets and inclined surfaces the maximum wetting width, $R_{\max }$, is located above or below the plane of impingement, depending on $\phi$ and $\lambda$ (see Figure 2(a)). The empirical approach is employed again to relate $2 R_{\max }$ to $2 R$. The location of $R_{\max }$ along the plate may be near the point of impingement for rivulet flow, and relatively far below the impingement point for gravity flow. It also can occur above the impingement plane for $\phi$ or $\lambda>90^{\circ} . R_{\max }$ is required for estimating the area wetted by the jet and, as the wetting rate (i.e. the mass flow rate per unit film width) is at a minimum at $R_{\max }$, this determines the stability of the falling film and the formation of dry patches (see Wang et al., 2013a).

Figure 6(a) shows the results obtained for horizontal jets impinging on vertical and inclined walls at low flow rates $\left(0.7 \mathrm{~g} \mathrm{~s}^{-1}\right.$ to $\left.2.3 \mathrm{~g} \mathrm{~s}^{-1}, R e_{\text {jet }}=435-990\right)$ at $20^{\circ} \mathrm{C}$ with the $d_{\mathrm{N}}=1 \mathrm{~mm}$ nozzle. The data for a vertical wall $\left(\lambda=90^{\circ}\right)$ lie close to the $R_{\max }=2 R$ locus reported by Wilson et al. (2012). With inclined surfaces, however, $R_{\max }$ is greater than $2 R$ : for $\lambda<90^{\circ}$, $R_{\max }$ exceeded $3 R$ at steeper angles of incidence. Figure $6(b)$ shows a similar trend with the $3 \mathrm{~mm}$ nozzle on glass, except that the data for the vertical wall $\left(\lambda=90^{\circ}\right)$ lie above the $R_{\max }=$ $2 R$ locus. The $\lambda=30^{\circ}$ and $45^{\circ}$ results differ noticeably, while those for $\lambda=60^{\circ}$ are similar to the other sets. Similar behaviour was observed on Perspex. Reliable estimates of $R_{\max }$ cannot therefore be obtained for $\lambda$ values noticeably different from $90^{\circ}$ using this approach. The relationship $R_{\max }=2 R$ will underestimate the width of the wetted region at its widest part, which is conservative in terms of calculating the wetted coverage, but will overpredict the minimum wetting rate. Film stability criteria based on wetting rates would have to be applied carefully. This is an area for future work.

\section{Paint Cleaning}

Paint cleaning tests were performed with vertical plates and horizontal jets, mimicking the Morison and Thorpe (2002) studies, but using lower flow rates $\left(\dot{m}=5.5,7.5\right.$ and $9.2 \mathrm{~g} \mathrm{~s}^{-1}$ with a $2 \mathrm{~mm}$ nozzle at $\left.20^{\circ} \mathrm{C}\right)$ than Morison and Thorpe's ( $\dot{m}=10-90 \mathrm{~g} \mathrm{~s}^{-1}$, generated from a single spray ball hole with $d_{\mathrm{N}}=1.6 \mathrm{~mm}, 2 \mathrm{~mm}$, and $2.4 \mathrm{~mm}$ ). The paint was easy to remove 
compared with the polyvinylacetate (PVA) and petroleum jelly layers investigated by Wilson et al. (2014). The stages in cleaning evident in Figure 7 are similar to those in Morison and Thorpe's study. The horizontal striations evident in the images were caused by the brushing used to apply the layer. Cleaning tests were performed in triplicate and the results and showed good reproducibility $( \pm 5 \%)$.

Initially a region cleared of paint grows radially outwards from the point of impingement in the RFZ. There is little change beyond the RFZ. Between $15 \mathrm{~s}$ and $60 \mathrm{~s}$, this cleaned area increased in size. The wetted area of the paint layer is evident in the images, and there is a hint of some paint at the edge of the draining zone starting to be removed by $60 \mathrm{~s}$. Removal is noticeable in the draining zone by $90 \mathrm{~s}$. The radial cleaning front reached the film jump by $120 \mathrm{~s}$ : the $R F Z$ is then clean and there is noticeable removal over the rest of the falling film region. Removal is evident over the whole wetted region after $210 \mathrm{~s}$.

The change in behaviour after $c .60 \mathrm{~s}$ suggests that there is a weakening of the blue paint layer after this time, so that the shear stresses or momentum generated by the rope and the falling film are sufficient to dislodge the material. Furthermore, all the blue paint was removed from the entire wetted region after longer times (depending on the flow rates), indicating the existence of a soaking and weakening step which was also observed by Morison and Thorpe (2002) in their experiments. The washable paint layer is not a model soil in terms of constant rheology: rather, it is subject to the wetting and weakening behaviour observed with many food soils and reported by other workers (e.g. Köhler et al. (2013) for layers of Xanthan gum).

Wilson et al. (2014) developed a one-dimensional model to describe the rate of cleaning in the $R F Z$ where cleaning occurs by adhesive failure. The model assumes that the soil layer has a uniform thickness, $\delta$, and constant rheology: changes in the thickness or strength of the layer with time due to soaking, swelling etc. are not considered. Adhesive failure causes the growth of a circular zone of radius $r_{c}$ free of soil which increases with cleaning time, $t$, according to the following equation, given by Wilson et al. (2014),

$$
r_{c} \approx \sqrt[5]{\frac{3 k^{\prime}}{\pi c} \dot{m}^{3}} \cdot\left(t-t_{i}\right)^{1 / 5}=K \cdot \Delta t^{0.2}
$$

where $t_{\mathrm{i}}$ is the time at which cleaning front is first seen, $k^{\prime}$ is a lumped cleaning rate constant, and $c$ is a lumped parameter which includes liquid viscosity and density. Plots of $r_{c}$ against $\Delta t^{0.2}$ should be linear with gradient $K$, where $K$ is an overall rate constant. Further details are 
given in Wilson et al. (2014) along with results for cleaning Xanthan gum, petroleum jelly and PVA layers.

The cleaning profiles for a series of horizontal jet tests are plotted in Figure 8. The diameter of the paint free region at the mid-plane was measured to give $r_{\mathrm{c}}$. Elapsed time since cleaning started is used instead of $t-t_{\mathrm{i}}$ because $t_{\mathrm{i}}$ was short (the trends suggest about $8 \mathrm{~s}$ ). Open symbols are used where $r_{c}$ was smaller than the $R$ value measured on a clean glass plate. The plots are quite linear in the interval $10<t<100 \mathrm{~s}\left(1.6 \mathrm{~s}^{0.2}<t^{0.2}<2.5 \mathrm{~s}^{0.2}\right)$, indicating that the model gives a reasonable description of the cleaning process. Non-linear behaviour is evident at longer times, and particularly when $r_{c}>R$ (i.e. the size of the radial flow zone). One of the reasons for this is that $r_{c}$ is measured at the mid-plane of the jet, and removal in the rope region becomes important at longer times owing to soaking. This is more noticeable at the higher flow rates as the flow rate in the rope is larger. After a long time the cleaned radius, $r_{c}$, is equal to $R_{c}$, the half-width of the wetted surface at the impingement level. The width of the cleaned region could extend beyond the initial value of $R_{\mathrm{c}}$ if the wet soil promoted wetting and changed the flow pattern: such behaviour was not observed in these tests.

The gradients of the cleaning profiles were calculated using data where $r_{c}<R$ and are plotted against $\dot{m}^{0.6}$, as directed by the model, in Figure 9. A linear relationship is evident, which is close to the strictly proportional trend expected from the model. The $K$ values for these paint layers are similar in magnitude to those obtained for thin $(\delta=70 \pm 30 \mu \mathrm{m})$ PVA layers reported by Wilson et al. (2014). The flow rates used in the latter study were larger. The $k^{\prime}$ value extracted from the gradient in Figure 8 was $0.72 \mathrm{~s} \mathrm{~m} \mathrm{~kg}^{-1}$, which is similar in magnitude to that obtained for the PVA layers $\left(k^{\prime}=0.16 \mathrm{~s} \mathrm{~m} \mathrm{~kg}^{-1}\right)$. The paint cleaned more quickly (larger $k^{\prime}$ ).

The relationship between $k^{\prime}$, layer thickness and rheology is the subject of ongoing work. The relatively simple fluid mechanics model discussed here provides a reasonable description of the flow in the RFZ and estimates of the draining zone width, which are necessary to quantify the effect of operating parameters and nozzle dimensions on the cleaning performance of the unit. 


\section{Extension to other cleaning operations}

The paint cleaning study has confirmed that the cleaning model reported by Wilson et al. can be applied to paint layers on vertical walls. Horizontal cleaning jets striking vertical walls (or vertical jets impinging on horizontal plates) are not common in tank cleaning applications but may be found in dishwashers, washing tunnels, in systems for washing vehicles (including military tanks), or where a jet of cleaning water strikes tank internals such as agitator blades or baffles. The results in the first section of the paper show that the extended Wang et al. (2013a) model can predict the flow pattern of the films formed on inclined walls, extending the scope of their work to both inclined jets and inclined walls. The model is written in a general form so that many of the jet-wall approach angles which may be found in industrial processes such as tank cleaning can be considered. Topics to be addressed in order to generate a truly predictive modelling framework for tank cleaning include $(i)$ combining these flow characteristics with the cleaning model of Wilson et al. (2014), to predict the evolution of quasi-elliptical cleaning fronts: (ii) including the motion of the jet, as industrial cleaning jets are rarely stationary (see Köhler et al, 2014); (iii) incorporating time-dependent soil layer behaviour, which will be affected by liquid draining from points higher up on the wall; and (iv) extension to higher flow rates, as the experiments reported here have employed relatively small water flow rates.

\section{CONCLUSIONS}

The flow patterns created by horizontal impinging liquid jets on inclined surfaces has been studied using $1 \mathrm{~mm}, 2 \mathrm{~mm}$ and $3 \mathrm{~mm}$ nozzles at flow rates ranging from $0.78-17.3 \mathrm{~g} \mathrm{~s}^{-1}$. The Wang et al. (2013b) model predicted the dimensions of the film jump reasonably well for angles of inclination, $\lambda, \leq 90^{\circ}$. For $\lambda>90^{\circ}$, the agreement was less good, which is attributed to gravity effects and the dynamics of the rope region. The width of the flow created by the impinging jet at the plane of impingement was described by the relationship $R_{\mathrm{c}}=2 R$ reasonably for $\lambda \leq 90^{\circ}$, where $R_{c}$ is the total film width and $R$ is the width at the film jump, being predictable from theory. However, the maximum width of the falling film generated by the impinging jet did not follow a simple relationship to $R$ for more acute or oblique orientations.

A short study of cleaning of dried blue paint layers from vertical glass surfaces by a horizontal jet, mimicking the experiments reported by Morison and Thorpe at the 2002 
meeting in this series of conferences, showed that the initial cleaning behaviour could be described well by the Wilson et al. (2014) adhesive failure model.

\section{ACKNOWLEDGEMENTS}

A PhD scholarship for TW from Chengda Engineering Co. is gratefully acknowledged. 


\section{References}

Blake, TD (2006) The physics of moving wetting lines, J. Coll. Interface Sci., 299, 1-13.

Gunjal, PR, Ranade VV and Chaudhari, RV (2005) Dynamics of drop impact on solid surface: experiments and VOF simulations, AIChEJ, 59-78.

Jensen, BBB (2011) Tank cleaning technology: Innovative application to improve clean-in-place (CIP), EHEDG Yearbook 2011/2012, publ. EHEDG, Frankfurt, 26-30.

Kate, RP, Das, PK and Chakraborty, S (2007) Hydraulic jumps due to oblique impingement of circular liquid jets on a flat horizontal surface. J. Fluid Mech., 573, 247-263.

Köhler, H, Stoye, H, Mauermann, M and Majschak, J-P (2013) Optimization approach for efficient cleaning with impinging jets - influence of nozzle diameter, pressure and nozzle distance, Proc $\mathrm{X}^{\text {th }}$ Intl. Conf. Heat Exchanger Fouling \& Cleaning, Budapest, June 2013.

Köhler, H., Stoye, H., Mauermann, M., Weyrauch, T. and Majschak, J-P. (2014) Cleaning efficiency which efficiency? Study of the influences of nozzle diameter, pressure and jet moving speed of impinging jets, Food \& Bioproducts Processing, under review.

Lienhard, JH, Liu, X and Gabour LA (1992) Splattering and heat transfer during impingement of a turbulent liquid jet. J. Heat Transfer, 114(2), 362-372.

Mertens, K., Putkaradze, V. and Vorobieff, P. (2005). Morphology of a stream flowing down an inclined plane. Part 1. Braiding. J. Fluid Mech., 531, 49-58.

Morison, KR and Thorpe, RJ (2002). Liquid distribution from cleaning-in-place sprayballs, Food Bioprod. Proc., 80, 270-275.

Stenby M, Detlefsen, MW and Jensen BBB (2011) New test method for rotating head performance in tank cleaning. J. Hygienic Eng. Des., 1, 40-43.

Wang, T, Tan, JSC, Faria, D, Stevens, LJ, Davidson, JF and Wilson, DI (2013a) Flow patterns and draining films created by horizontal and inclined water jets impinging on vertical walls. Chem. Eng. Sci. 102, 585-601.

Wang, T, Davidson, JF and Wilson, DI (2013b) Effect of surfactant on flow patterns and draining films created by a static horizontal liquid jet impinging on a vertical surface at low flow rates, Chem. Eng. Sci. 88, 79-94.

Wang, T. (2014) PhD Dissertation, University of Cambridge.

Watson, EJ (1964) The radial spread of a liquid jet over a horizontal plane, J. Fluid Mech., 20(3), 481-499. 35 .

Wilson, DI, Fryer, PJ and Hasting, APM (2002) Fouling, Cleaning and Disinfection in Food Processing, Conference Proceedings, publ. Department of Chemical Engineering, Cambridge.

Wilson, DI, Atkinson, P, Köhler, H, Mauermann, M, Stoye, H, Suddaby, K, Wang, T, Davidson, JF and Majschak, J-P (2014) Cleaning of soft-solid soil layers on vertical and horizontal surfaces by stationary coherent impinging liquid jets. Chem. Eng. Sci., 109, 183-196.

Wilson, DI, Le, BL, Dao, HDA, Lai, KY, Morison, KR and Davidson, JF (2012) Surface flow and drainage films created by horizontal impinging liquid jets, Chem. Eng. Sci., 68, 449-460. 


\section{Nomenclature}

\section{Roman}

$c \quad$ group of parameters, Eqn. [3]

$\mathrm{kg}^{2} \mathrm{~m}^{-4} \mathrm{~s}^{-1}$

$d_{\mathrm{N}} \quad$ nozzle diameter

$\mathrm{m}$

$g \quad$ gravitational acceleration

$\mathrm{m} \mathrm{s}^{-2}$

$k^{\prime} \quad$ cleaning rate constant

$\mathrm{s} \mathrm{m} \mathrm{kg}{ }^{-1}$

$K \quad$ lumped cleaning rate constant

$\mathrm{m} \mathrm{s}^{-0.2}$

$\dot{m} \quad$ mass flow rate

$\mathrm{kg} \mathrm{s}^{-1}$

PVA polyvinylacetate

$r \quad$ radial co-ordinate

$\mathrm{m}$

$r_{\mathrm{c}}$ radius of cleaned area $\mathrm{m}$

$\begin{array}{lll}r_{\mathrm{e}} & \text { radius of impingement ellipse at angle } \theta & \mathrm{m}\end{array}$

$r_{\mathrm{o}} \quad$ radius of jet

$\mathrm{m}$

$R F Z$ radial flow zone

$R \quad$ radius of $\mathrm{RFZ}$ at the midplane

$\mathrm{m}$

$R^{2} \quad$ correlation coefficient

$R_{\mathrm{c}} \quad$ outer radius of rope at the midplane $\mathrm{m}$

$R_{\max } \quad$ maximum half-width of falling fim $\quad \mathrm{m}$

$R_{\theta} \quad$ radius of RFZ at angle $\theta \quad \mathrm{m}$

$R e_{\text {jet }} \quad$ Reynolds number in jet, $=2 r_{o} U_{o} / v$

$t$ time

$t_{\mathrm{i}} \quad$ time at which breakthrough is first seen $\mathrm{m}$

$U$ mean velocity in film $\mathrm{m} \mathrm{s}^{-1}$

$U_{\mathrm{o}} \quad$ velocity of jet $\mathrm{m} \mathrm{s}^{-1}$

$Z_{\mathrm{r}}$ height of RFZ at $\theta=0 \quad \mathrm{~m}$

$\begin{array}{lll}Z_{\mathrm{t}} & \text { distance to top of rope at } \theta=0 & \mathrm{~m}\end{array}$

Greek

$\alpha \quad$ angle of the jet to the horizontal $\circ$

$\beta \quad$ contact angle $\quad \circ$

$\delta$ layer thickness $\quad \mathrm{m}$ 
$\gamma \quad$ surface tension

$\mathrm{N} \mathrm{m}^{-1}$

$\rho \quad$ density

$\mathrm{kg} \mathrm{m}^{-3}$

$\lambda \quad$ angle of inclination of the plate to the horizontal

$\circ$

$\theta \quad$ azimuthal angle of streamline along the plate (Figure 1(b))

$\phi \quad$ angle at which the jet strikes the plate

○

$\mu \quad$ dynamic viscosity

$\mathrm{Pa} \mathrm{s}$

$v \quad$ kinematic viscosity

$\mathrm{m}^{2} \mathrm{~s}^{-1}$ 


\section{Tables}

Table 1: Summary of falling film behaviour observed at low flow rates at $20^{\circ} \mathrm{C}$. Horizontal jets $(\alpha=0)$.

\begin{tabular}{|c|c|c|c|c|c|c|c|c|c|c|c|}
\hline \multirow{2}{*}{$\begin{array}{l}d_{N} \\
\mathrm{~mm}\end{array}$} & \multirow{2}{*}{$\begin{array}{l}\text { Mass flow } \\
\text { rate } \\
\dot{m} \\
\mathrm{~g} \mathrm{~s}^{-1}\end{array}$} & \multirow{2}{*}{$\begin{array}{c}U_{o} \\
\mathrm{~m} \mathrm{~s}^{-1}\end{array}$} & \multirow[t]{2}{*}{$R e_{\text {jet }}$} & \multicolumn{4}{|c|}{$\begin{array}{c}\text { glass } \\
\text { Flow pattern at surface } \\
\text { inclined at angle } \lambda\left[{ }^{\circ}\right]\end{array}$} & \multicolumn{4}{|c|}{$\begin{array}{c}\text { Perspex } \\
\text { Flow pattern at surface } \\
\text { inclined at angle } \lambda\left[{ }^{\circ}\right]\end{array}$} \\
\hline & & & & 45 & 60 & 90 & 120 & 45 & 60 & 90 & 120 \\
\hline \multirow{2}{*}{1} & $0.68-1.55$ & $0.87-1.98$ & $435-990$ & $\mathrm{R}$ & $\mathrm{R}$ & $\mathrm{R}$ & $\mathrm{R} / \mathrm{RR}$ & $\mathrm{R}$ & $\mathrm{R}$ & $\mathrm{R}$ & $\mathrm{R}$ \\
\hline & $1.7-2.13$ & $2.16-2.71$ & $1080-1355$ & $\mathrm{R}$ & $\mathrm{R}$ & $\mathrm{R}$ & $\mathrm{R} / \mathrm{RR}$ & $\mathrm{R}$ & $\mathrm{R}$ & $\mathrm{R}$ & $\mathrm{R} / \mathrm{RR}$ \\
\hline \multirow{2}{*}{2} & $3.7-7.5$ & $1.17-2.39$ & $1170-2390$ & $\mathrm{R}$ & $\mathrm{R}$ & G-R & $\mathrm{R}$ & $\mathrm{R}$ & $\mathrm{R}$ & G-R & $\mathrm{R}$ \\
\hline & $8.1-9.9$ & $2.58-3.17$ & $2580-3170$ & $\mathrm{R}$ & $\mathrm{R}$ & $\mathrm{G}$ & $\mathrm{RR}$ & $\mathrm{R}$ & $\mathrm{R}$ & G & $\mathrm{R} / \mathrm{RR}$ \\
\hline \multirow{2}{*}{3} & $7.0-13.0$ & $0.995-1.85$ & $995-1847$ & G-R & G-R & G & G-R & $\mathrm{R}$ & $\mathrm{R}$ & G-R & G-R \\
\hline & $14.1-17.3$ & $2.0-2.45$ & $2000-2450$ & G & $\mathrm{G}$ & G & $\mathrm{G} / \mathrm{RR}$ & $\mathrm{G}$ & G-R & G & $\mathrm{G} / \mathrm{RR}$ \\
\hline
\end{tabular}

Key: $\mathrm{R}$ - rivulet flow; $\mathrm{RR}$ - multi-rivulet flow; $\mathrm{G}$ - wide (gravity) flow; G-R - transition from rivulet to gravity flow as flow rate is increased; $\mathrm{G} / \mathrm{RR}$ - gravity or multi-rivulet flow; R/RR - rivulet or multi-rivulet flow. 


\section{List of Figure captions}

Figure 1: Impinging jet geometry $(a)$ side view, $(b)$ end view, normal to the impact plate, showing a wide falling film (gravity flow). O marks the point of impingement. The small black region around $\mathrm{O}$ is the impingement ellipse, with polar radius $r_{\mathrm{e}}=f(\theta)$.

Figure 2: Photographs of film created by a horizontal jet impinging on inclined glass surface at $\lambda$ values of $(a) 45^{\circ} ;(b) 60^{\circ}$, (c) $60^{\circ}$, at $\dot{m}=7.5 \mathrm{~g} \mathrm{~s}^{-1}, d_{\mathrm{N}}=2 \mathrm{~mm}$. Scale bar is common to all images.

Figure 3 Effect of jet mass flow rate, $\dot{m}$, on impingement zone width, $2 R$, and height, $Z_{\mathrm{r}}$, for horizontal jets impinging on inclined glass and Perspex surfaces at (a) $\lambda=45^{\circ}$; (b) $\lambda=$ $60^{\circ}$; (c) $\lambda=120^{\circ}$. Labelled loci show the predictions of the inclined surface model, based on Equations [1] and [2], for $Z_{\mathrm{r}}$ and $2 R$, using measured values of $\beta$. Symbol size reflects $R$ and $Z$ measurement accuracy.

Figure 4: Correlation between $2 R_{\mathrm{c}}$ and $2 R$, for horizontal jets impinging on inclined glass surfaces at $20^{\circ} \mathrm{C}$. $(a) d_{\mathrm{N}}=1 \mathrm{~mm}, \dot{m}=0.7-2.3 \mathrm{~g} \mathrm{~s}^{-1},(b) d_{\mathrm{N}}=3 \mathrm{~mm}, \dot{m}=7-17.3 \mathrm{~g} \mathrm{~s}^{-1}$. $\lambda=30^{\circ}-120^{\circ}$.

Figure 5: Correlation between $2 R_{\mathrm{c}}$ and $2 R$, for horizontal jets impinging on inclined $(a)$ glass and $(b)$ Perspex surfaces at $20^{\circ} \mathrm{C}$, with $d_{\mathrm{N}}=2 \mathrm{~mm}, \dot{m}=3.7-9.9 \mathrm{~g} \mathrm{~s}^{-1} . \lambda=30^{\circ}-120^{\circ}$.

Figure 6: Relationship between widest part of film, $2 R_{\max }$, and $2 R$ for horizontal jet impinging on an inclined glass surface at $20^{\circ} \mathrm{C}$. $(a) d_{\mathrm{N}}=1 \mathrm{~mm}, \dot{m}=0.7 \mathrm{~g} \mathrm{~s}^{-1}$ to $2.3 \mathrm{~g} \mathrm{~s}^{-1},(b) d_{\mathrm{N}}=$ $3 \mathrm{~mm}, \dot{m}=0.7 \mathrm{~g} \mathrm{~s}^{-1}$ to $2.3 \mathrm{~g} \mathrm{~s}^{-1}$.

Figure 7: Erosion of washable blue paint from a vertical glass plate by a horizontal water jet. $d_{\mathrm{N}}=2 \mathrm{~mm}, \dot{m}=7.5 \mathrm{~g} \mathrm{~s}^{-1}\left(U_{\mathrm{o}}=2.39 \mathrm{~m} \mathrm{~s}^{-1}\right)$ at $20^{\circ} \mathrm{C} . R$ and $R_{\mathrm{c}}$ for similar jet on a clean glass plate are marked.

Figure 8: Evolution of the cleaning front location for a horizontal water jet impinging on vertical glass plates coated with blue paint, presented in the form of Equation [3] with $\Delta t=t$, the elapsed time. $\dot{m}$ values for each test given in the legend. The data points represent experimental measurements of the radius of the cleaned zone. Open symbols indicate where $r_{\mathrm{c}}<R$, where $R$ gives the location of the film jump on a clean plate, see Figure $1(b)$. The horizontal loci show experimental measurements of $R_{\mathrm{c}}$, shown in Figure $1(b)$, for a given $\dot{m}$ on a clean plate. Note that experimental measurements of $r_{\mathrm{c}}$ at high values of $t$ agree well with the measured values of $R_{\mathrm{c}}$.

Figure 9: Effect of $\dot{m}$ on lumped cleaning rate constant, $K$, for paint layers in Figure 7. Solid locus shows line of best fit, $K=0.463 \dot{m}^{0.6}-0.0051\left(R^{2}=0.9997\right)$. Dashed locus shows fit to model, Equation [3], $K=0.377 \dot{m}^{0.6}$.

Figure A1. Data in Figure 3, replotted as $Z_{\mathrm{r}} / R$. The $x$ axis represents the mass flow rate, as $R$ increases monatonically with $\dot{m}$. 
(a)

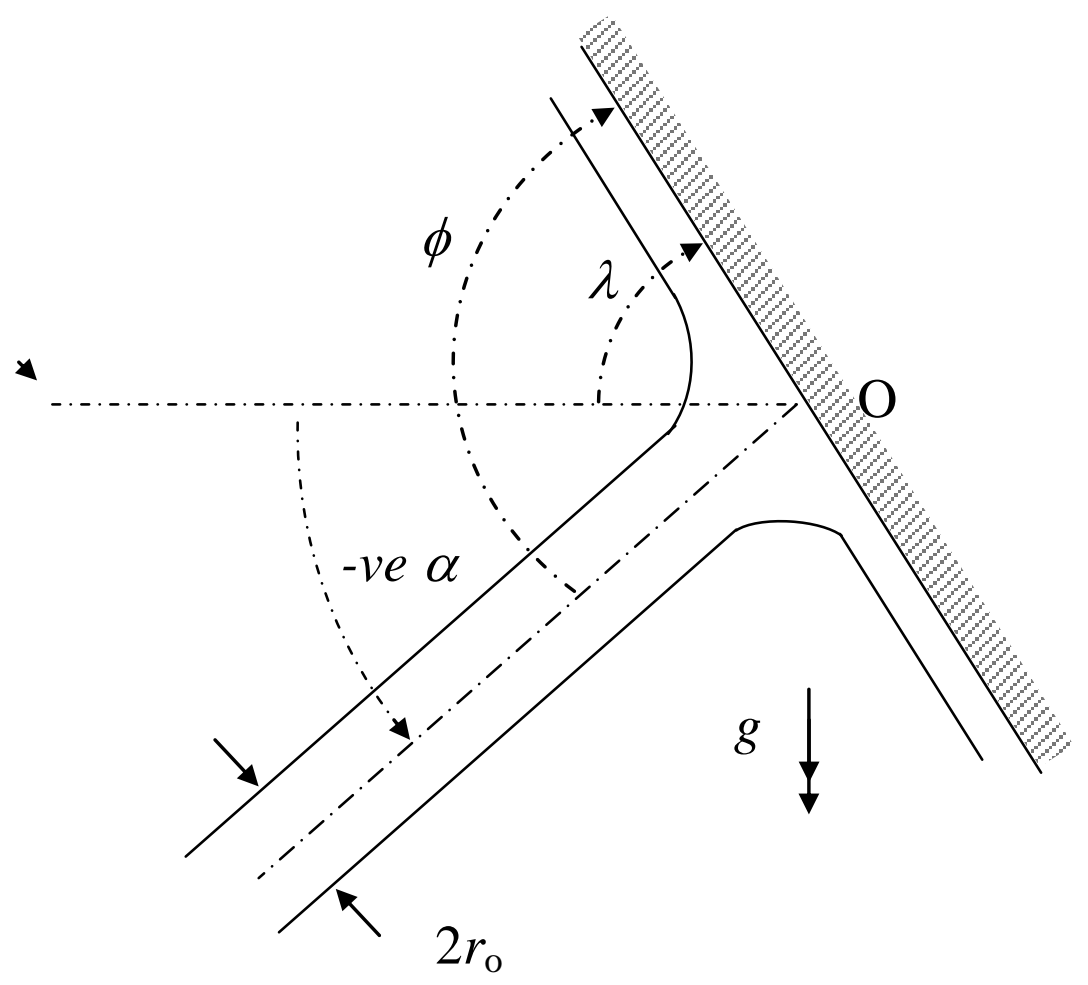

(b)

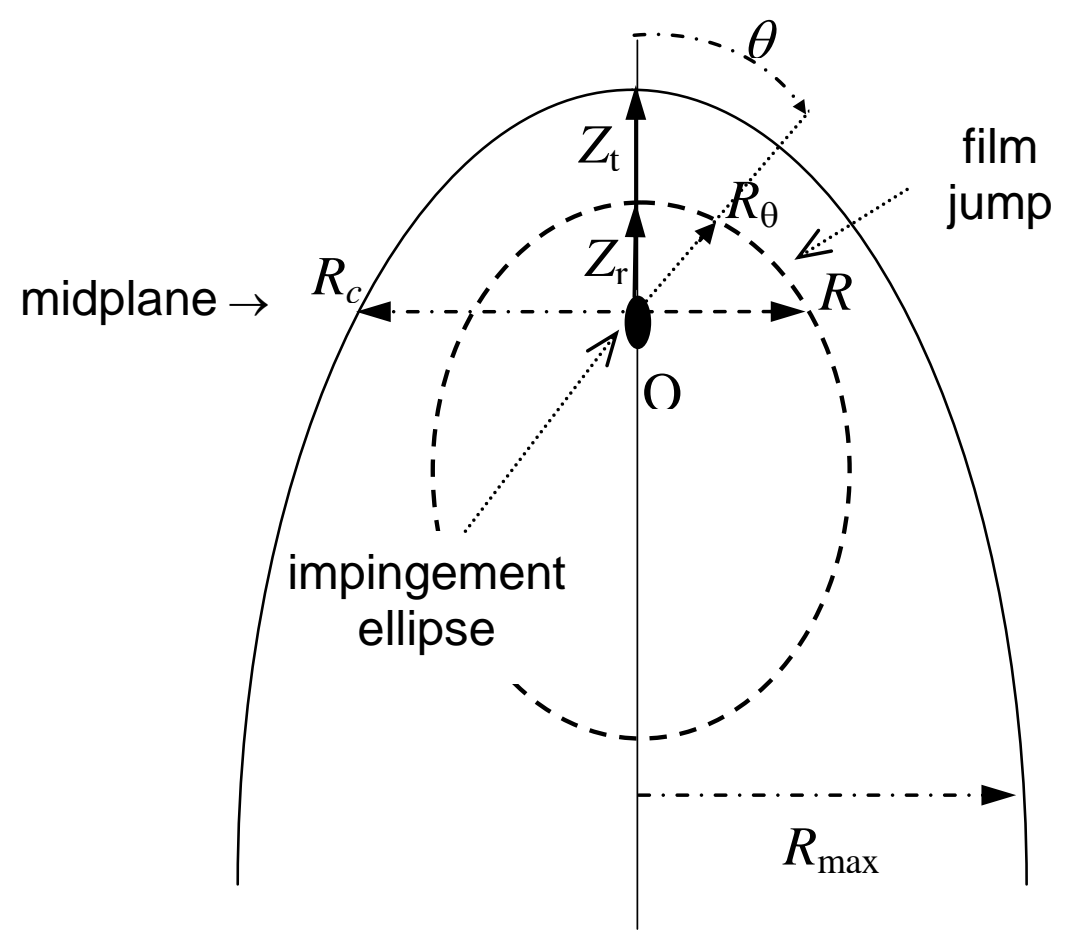

Figure 1: Impinging jet geometry $(a)$ side view, $(b)$ end view, normal to the impact plate, showing a wide falling film (gravity flow). O marks the point of impingement. The small black region around $\mathrm{O}$ is the impingement ellipse, with polar radius $r_{\mathrm{e}}=f(\theta)$. 


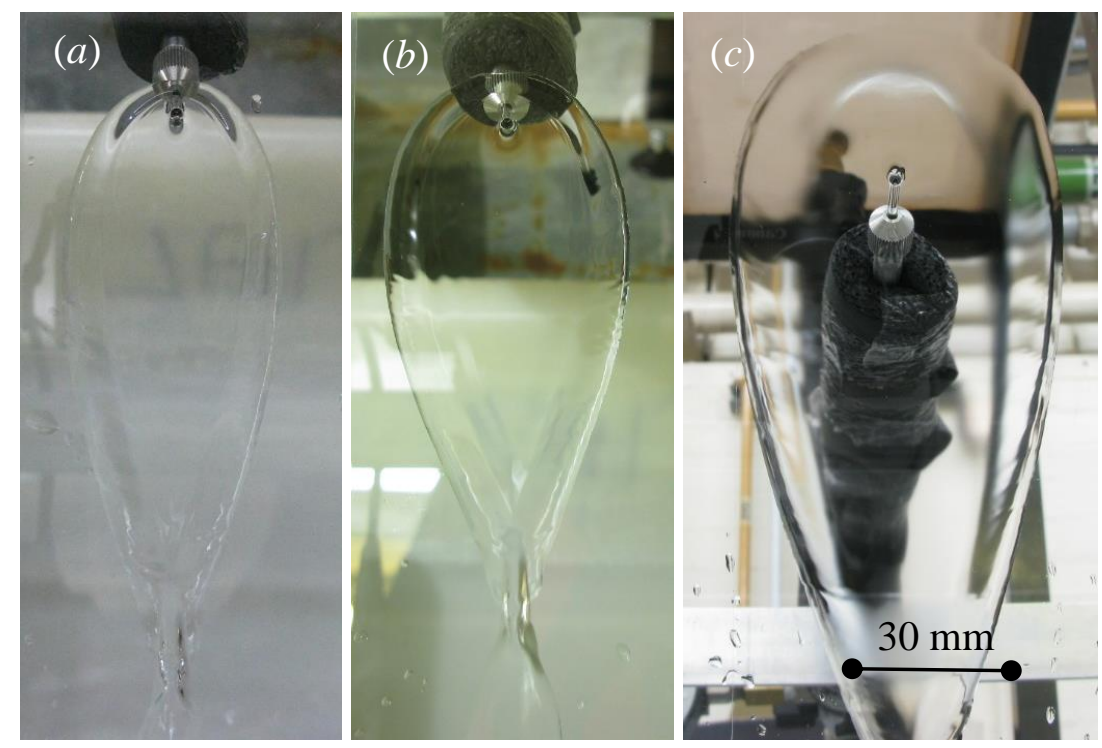

Figure 2: Photographs of film created by a horizontal jet impinging on inclined glass surface at $\lambda$ values of $(a) 45^{\circ} ;(b) 60^{\circ},(c) 60^{\circ}$, at $\dot{m}=7.5 \mathrm{~g} \mathrm{~s}^{-1}, d_{\mathrm{N}}=2 \mathrm{~mm}$. Scale bar in $(d)$ is common to all images. 
(a)

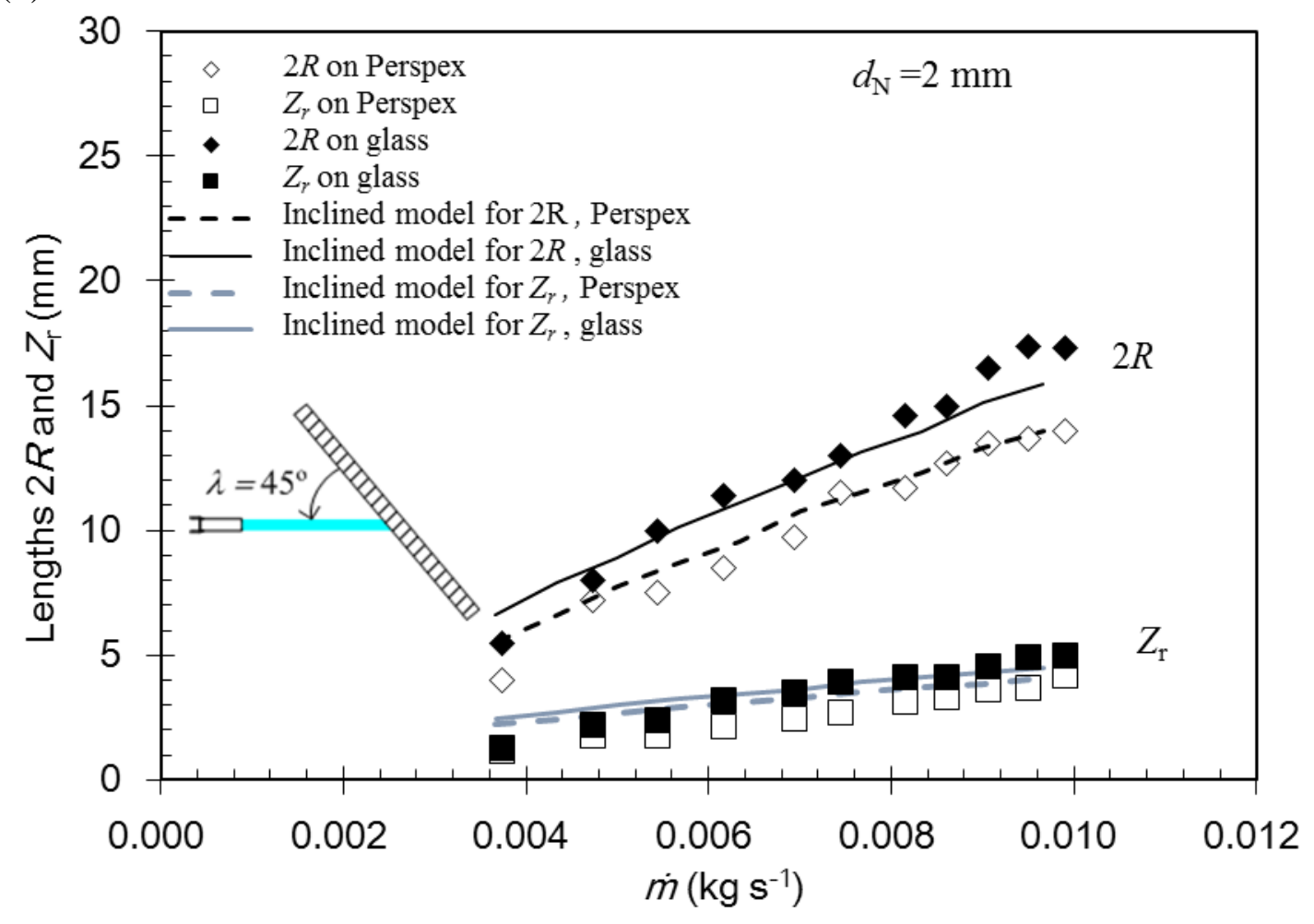

(b)

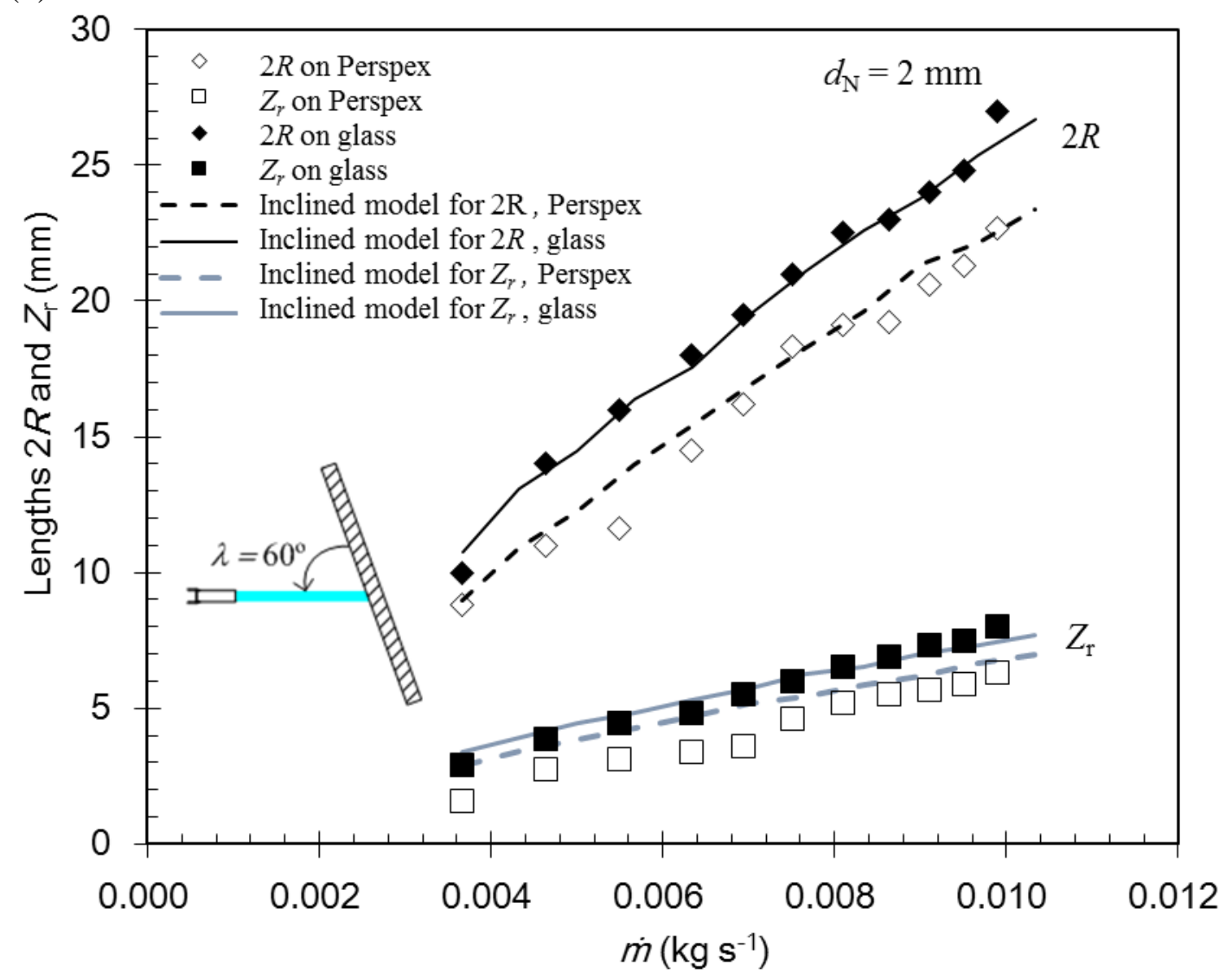


(c)

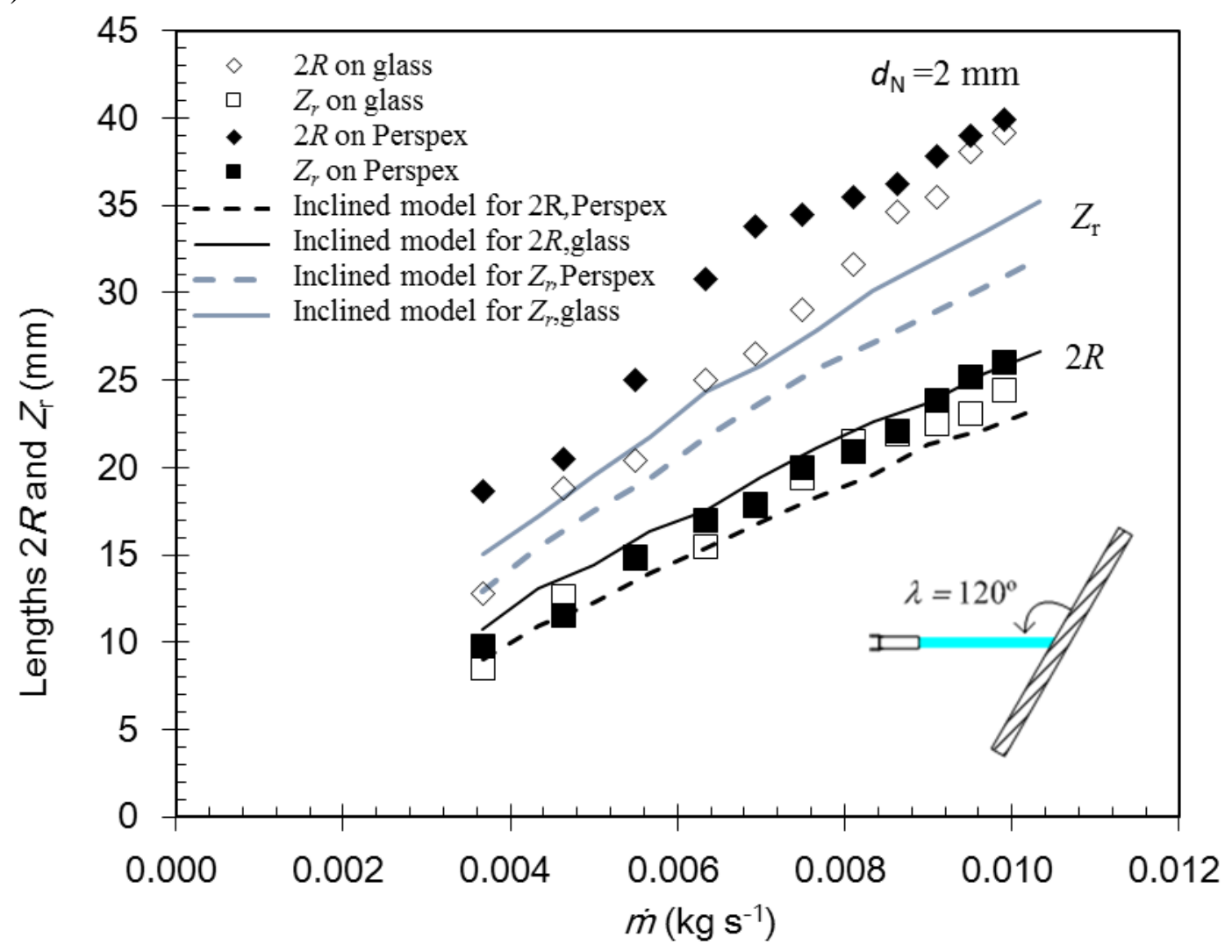

Figure 3 Effect of jet mass flow rate, $\dot{m}$, on impingement zone width, $2 R$, and height, $Z_{\mathrm{r}}$, for horizontal jets impinging on inclined glass and Perspex surfaces at (a) $\lambda=45^{\circ}$; (b) $\lambda=$ $60^{\circ}$; (c) $\lambda=120^{\circ}$. Labelled loci show the predictions of the inclined surface model, based on Equations [1] and [2], for $Z_{\mathrm{r}}$ and $2 R$, using measured values of $\beta$. Symbol size reflects $R$ and $Z$ measurement accuracy. 
(a)

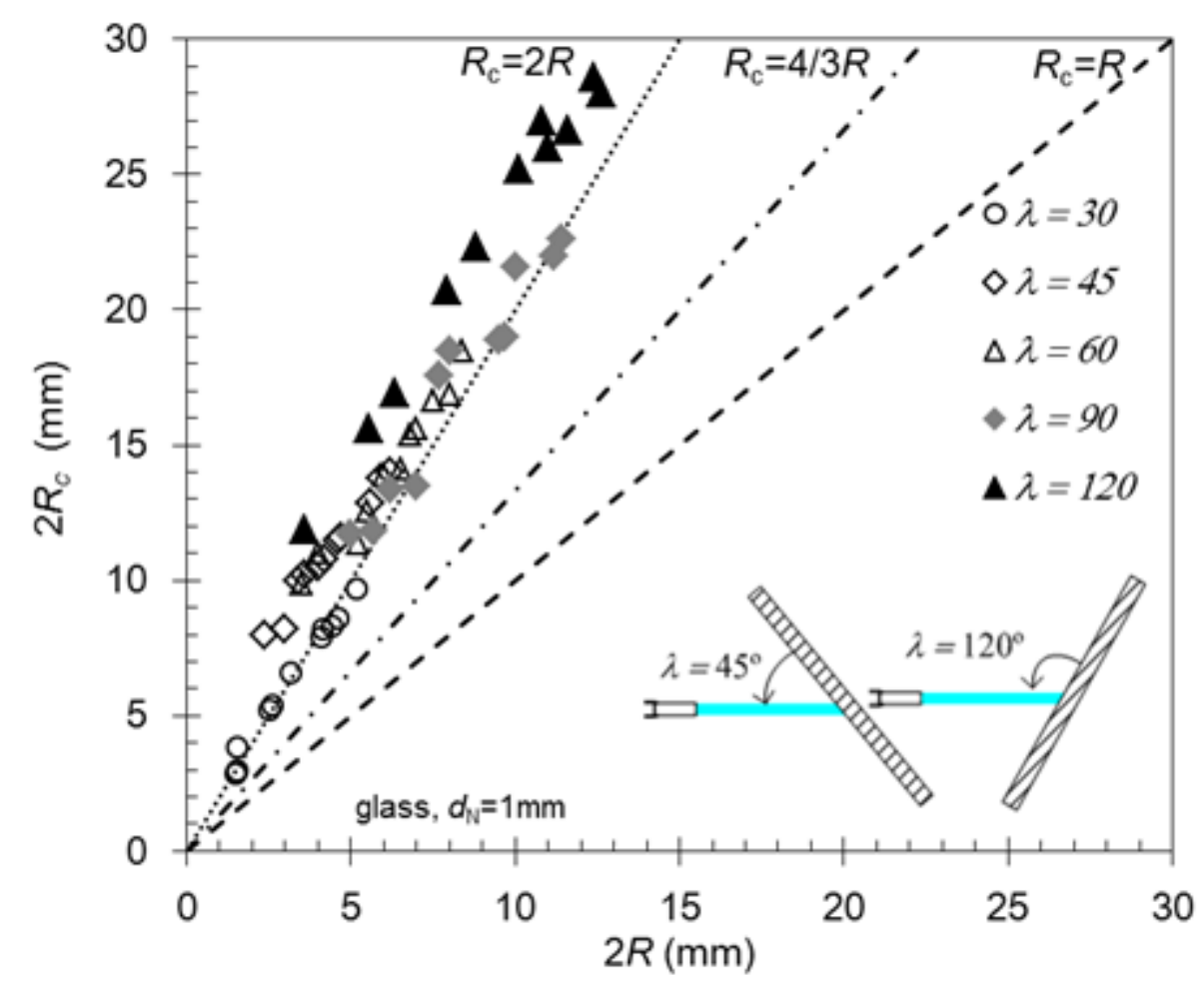

(b)

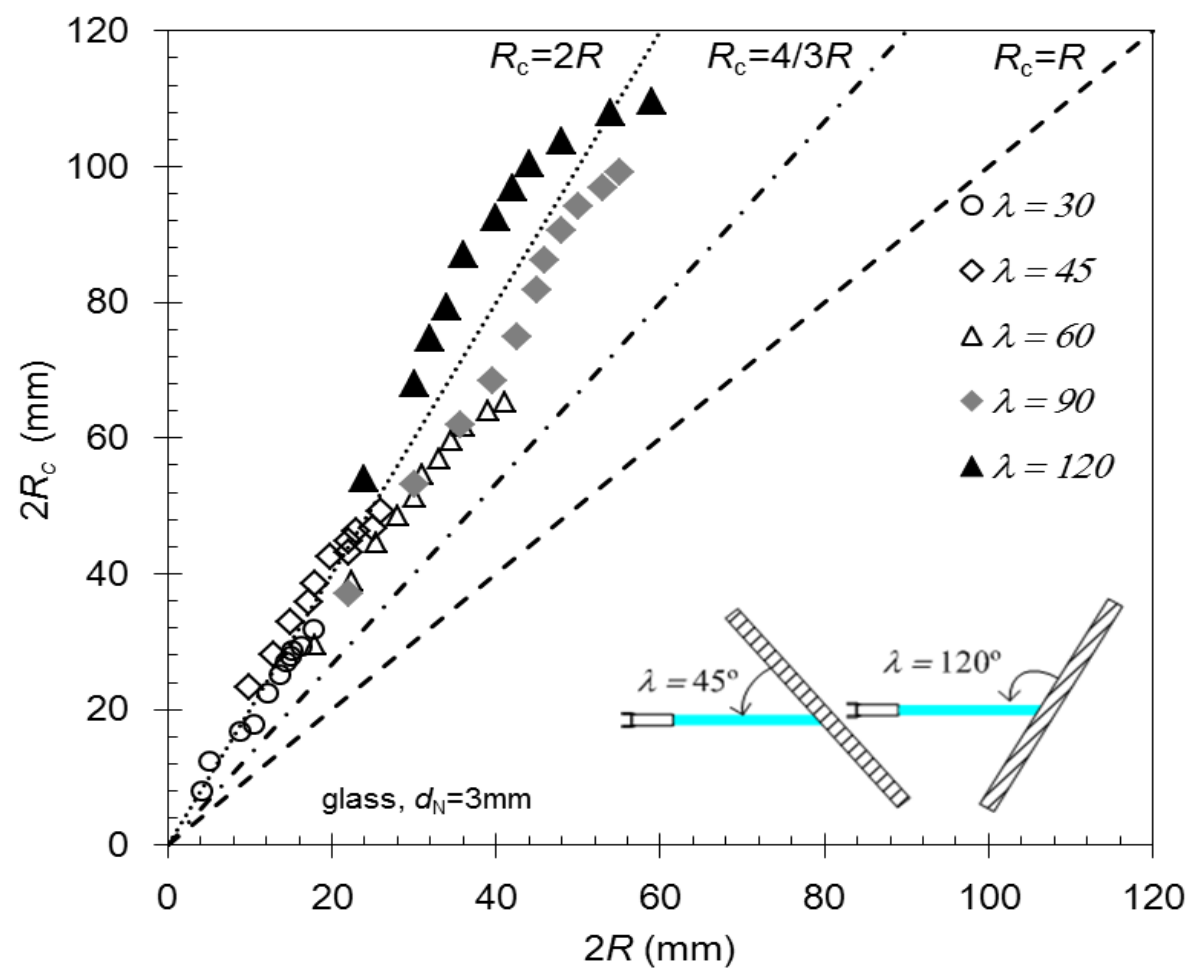

Figure 4: Correlation between $2 R_{\mathrm{c}}$ and $2 R$, for horizontal jet impinging on inclined glass surfaces at $20^{\circ} \mathrm{C} .(a) d_{\mathrm{N}}=1 \mathrm{~mm}, \dot{m}=0.7-2.3 \mathrm{~g} \mathrm{~s}{ }^{-1},(b)$ $d_{\mathrm{N}}=3 \mathrm{~mm}, \dot{m}=7-17.3 \mathrm{~g} \mathrm{~s}^{-1} . \lambda=30^{\circ}-120^{\circ}$. 
(a)

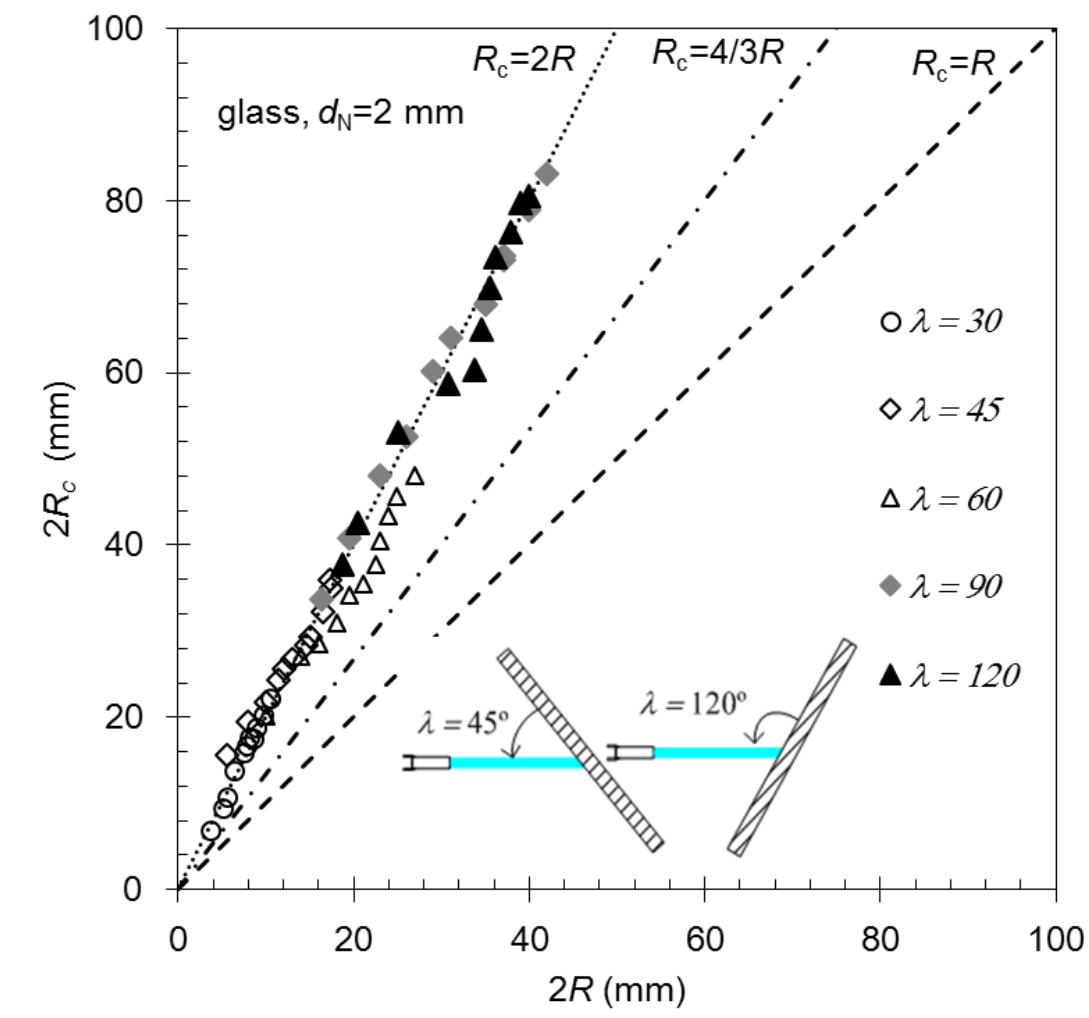

(b)

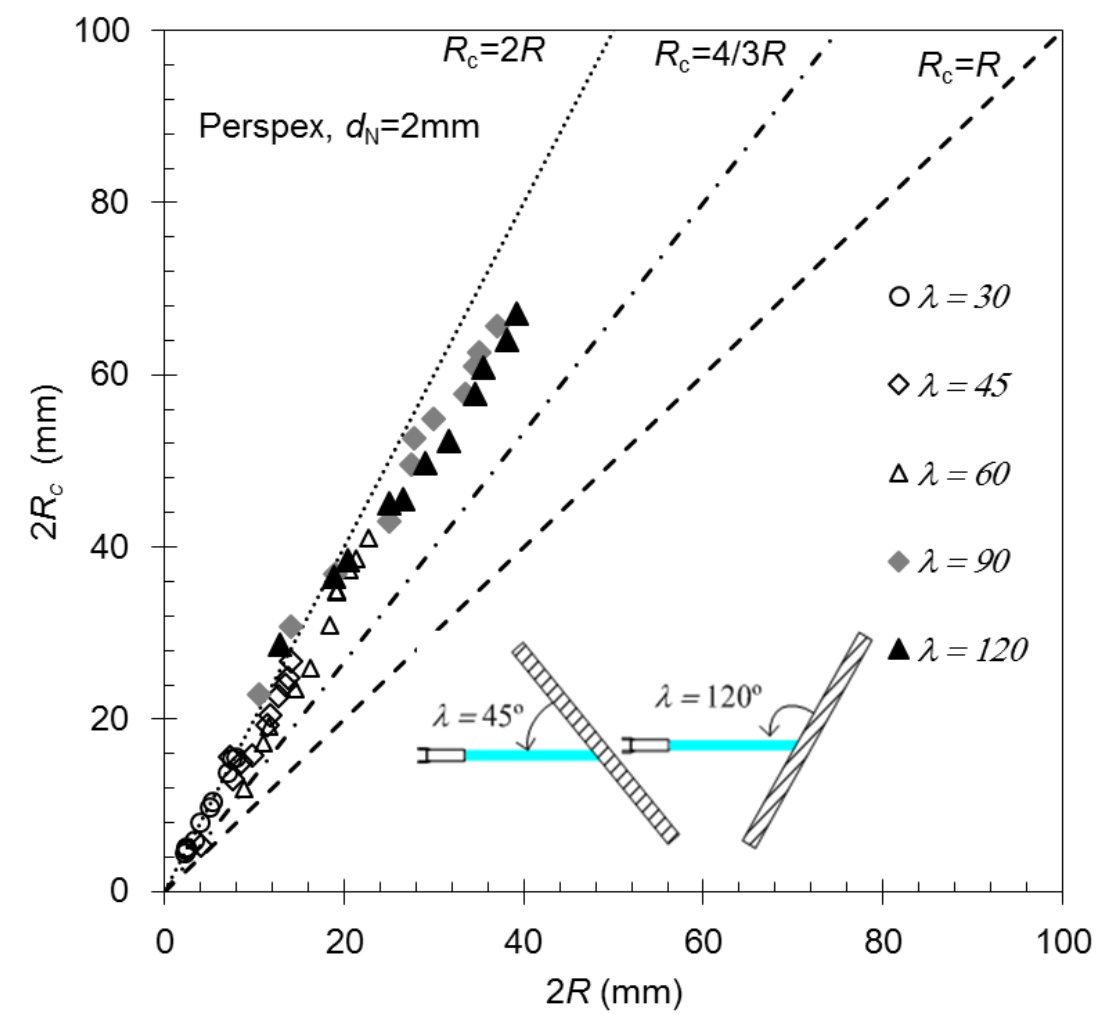

Figure 5: Correlation between $2 R_{\mathrm{c}}$ and $2 R$, for horizontal jet impinging on inclined $(a)$ glass and $(b)$ Perspex surfaces at $20^{\circ} \mathrm{C}$, with $d_{\mathrm{N}}=2 \mathrm{~mm}$, $\dot{m}=3.7-9.9 \mathrm{~g} \mathrm{~s}^{-1} ; \lambda=30^{\circ}-120^{\circ}$. 
(a)

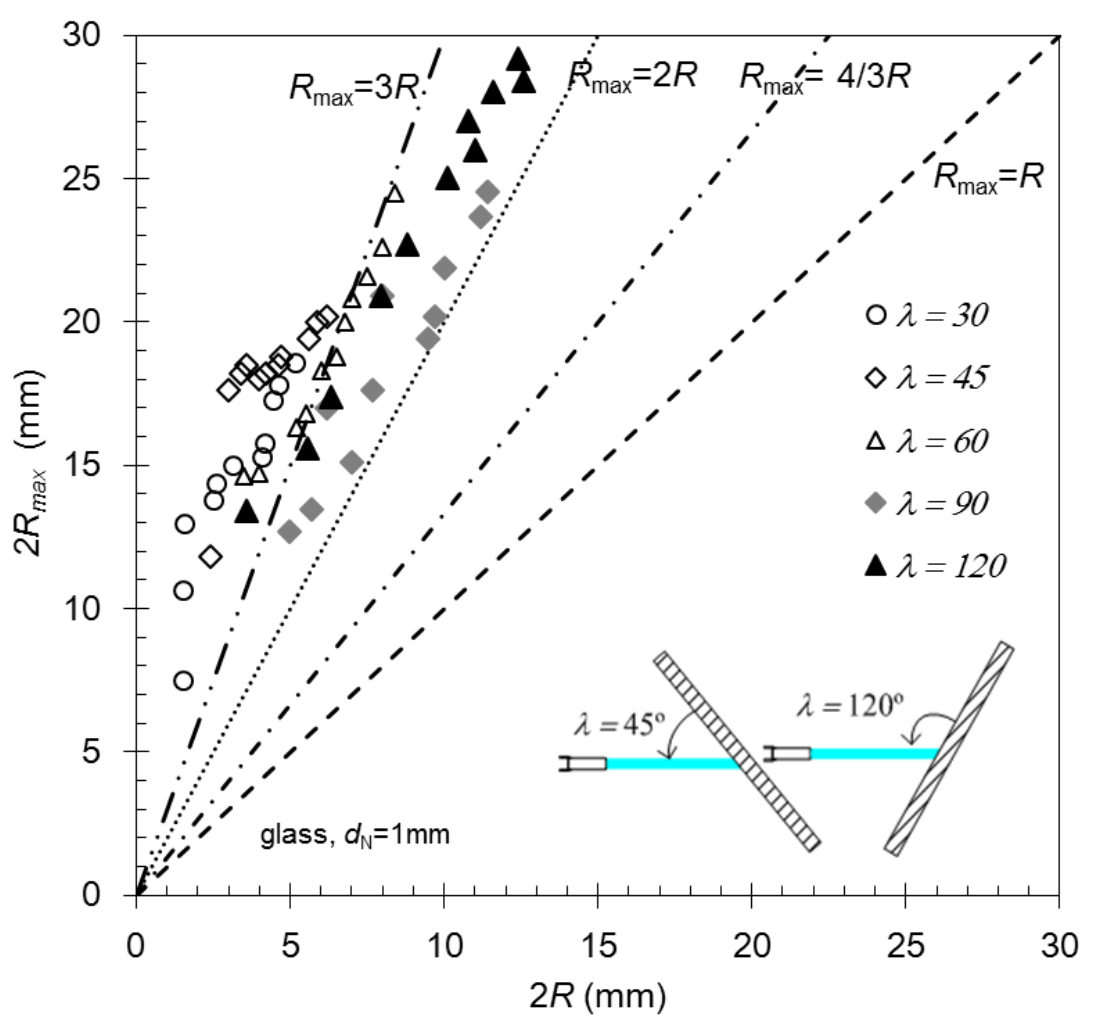

(b)

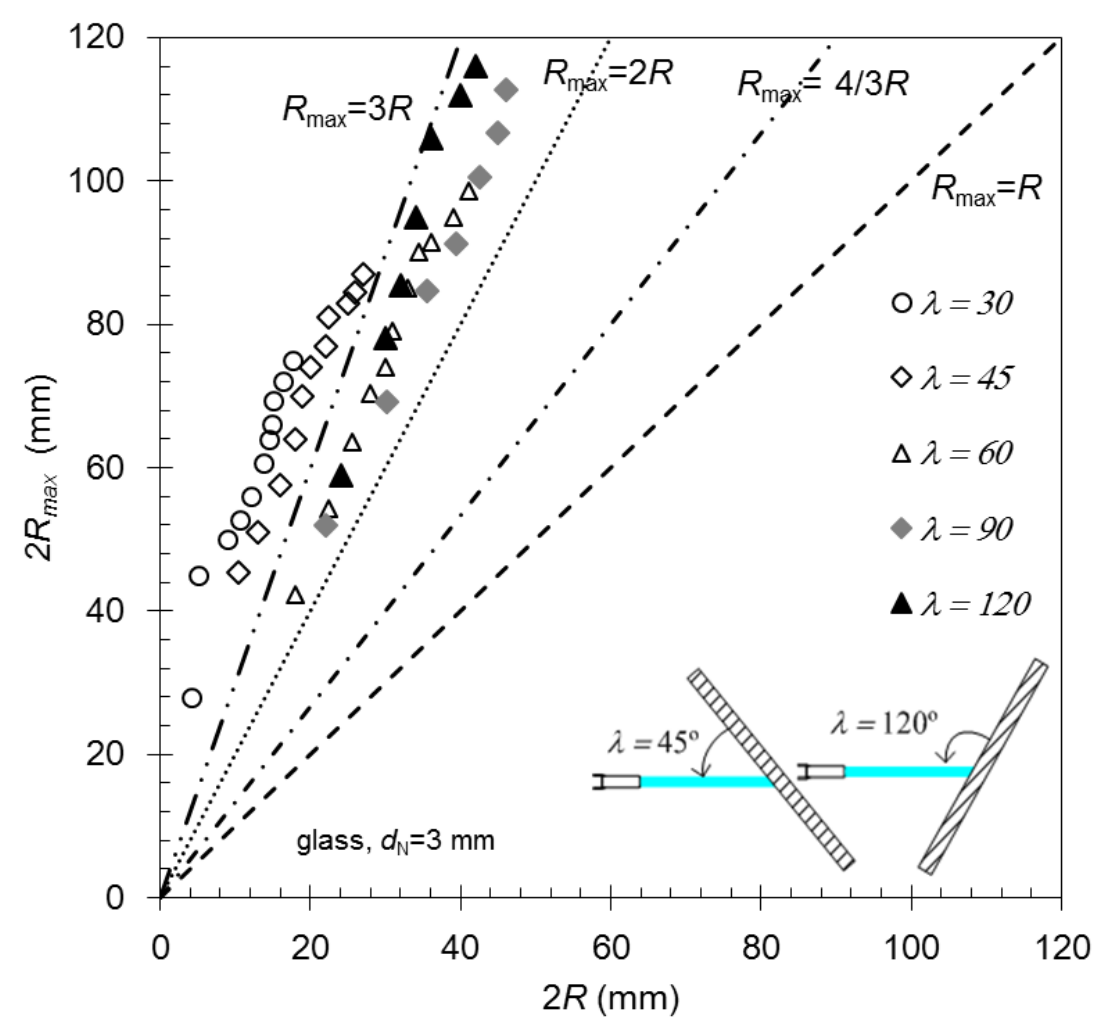

Figure 6: Relationship between the greatest film width, $2 R_{\max }$, and the film width $2 R$ at the level of impingement for a horizontal water jet impinging on an inclined glass surface at $20^{\circ} \mathrm{C}$. (a) $d_{\mathrm{N}}=1 \mathrm{~mm}, \dot{m}=0.7 \mathrm{~g} \mathrm{~s}^{-1}$ to $2.3 \mathrm{~g} \mathrm{~s}^{-1},(b) d_{\mathrm{N}}=3 \mathrm{~mm}, \dot{m}=0.7 \mathrm{~g} \mathrm{~s}^{-1}$ to $2.3 \mathrm{~g} \mathrm{~s}^{-1}$. 

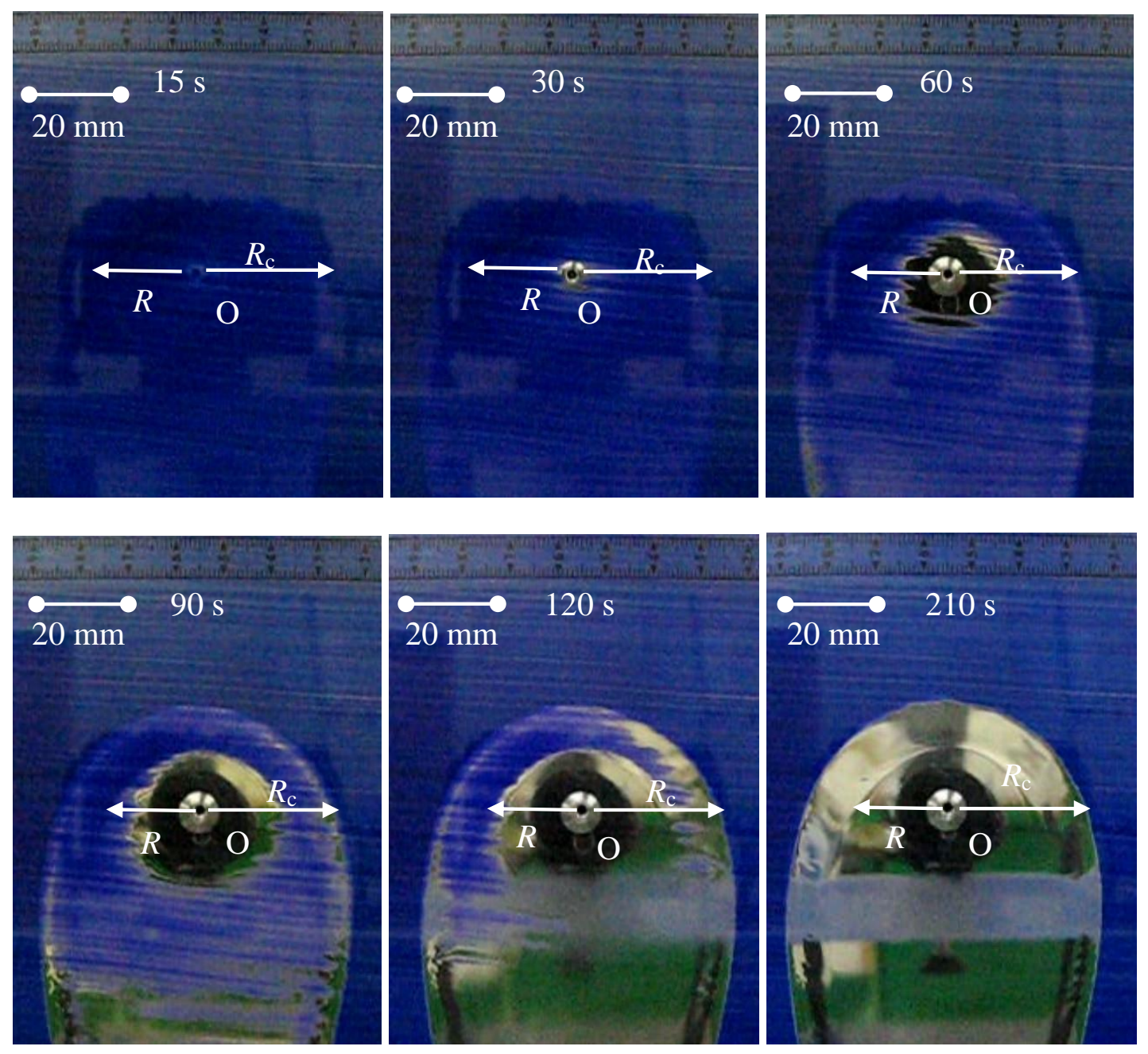

Figure 7: Erosion of washable blue paint from a vertical glass plate by a horizontal water jet. $d_{\mathrm{N}}=2 \mathrm{~mm}, \dot{m}=7.5 \mathrm{~g} \mathrm{~s}^{-1}\left(U_{\mathrm{o}}=2.39 \mathrm{~m} \mathrm{~s}^{-1}\right)$ at $20^{\circ} \mathrm{C} . R$ and $R_{\mathrm{c}}$ for similar jet on a clean glass plate are marked. 


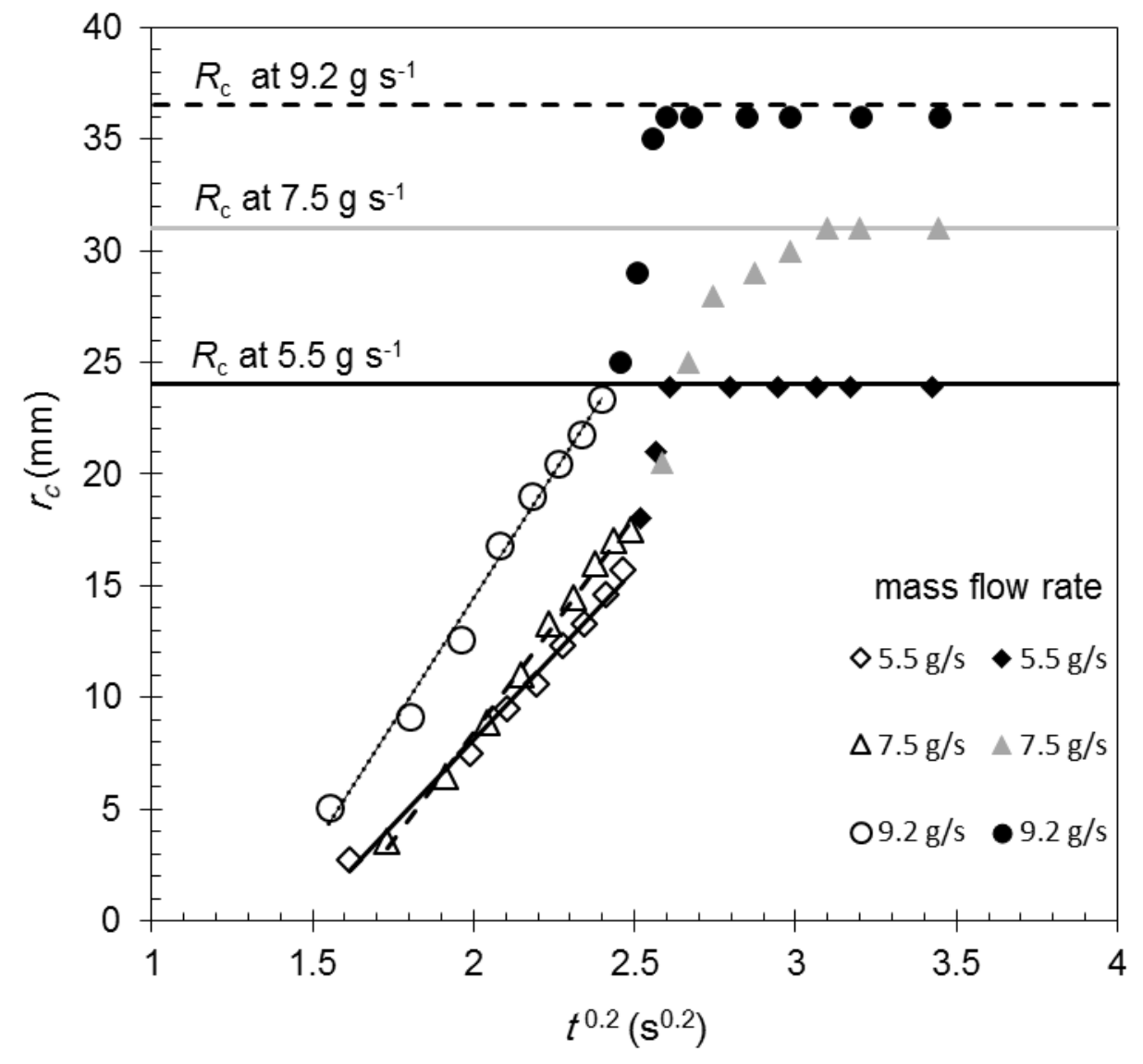

Figure 8: Evolution of the cleaning front location for a horizontal water jet impinging on vertical glass plates coated with blue paint, presented in the form of Equation [3] with $\Delta t=t$, the elapsed time. $\dot{m}$ values for each test given in the legend. The data points represent experimental measurements of the radius of the cleaned zone. Open symbols indicate where $r_{\mathrm{c}}<R$, where $R$ gives the location of the film jump on a clean plate, see Figure $1(b)$. The horizontal loci show experimental measurements of $R_{\mathrm{c}}$, shown in Figure $1(b)$, for a given $\dot{m}$ on a clean plate. Note that experimental measurements of $r_{\mathrm{c}}$ at high values of $t$ agree well with the measured values of $R_{\mathrm{c}}$. 


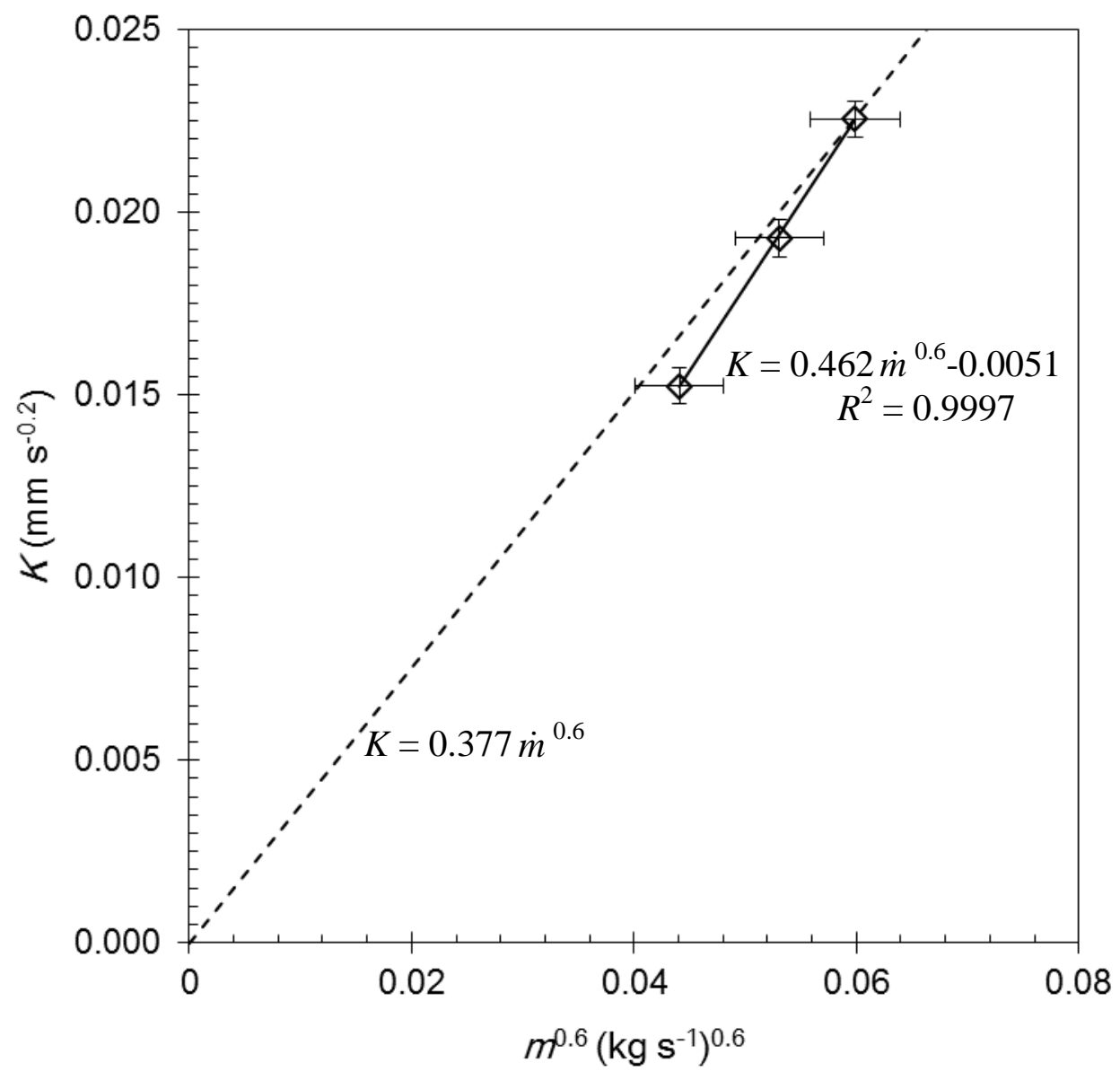

Figure 9: Effect of $\dot{m}$ on lumped cleaning rate constant, $K$, for paint layers in Figure 7. Solid locus shows line of best fit, $K=0.463 \dot{m}^{0.6}-0.0051\left(R^{2}=0.9997\right)$. Dashed locus shows fit to model, Equation [3], $K=0.377 \dot{m}^{0.6}$. 
Appendix Figure A1

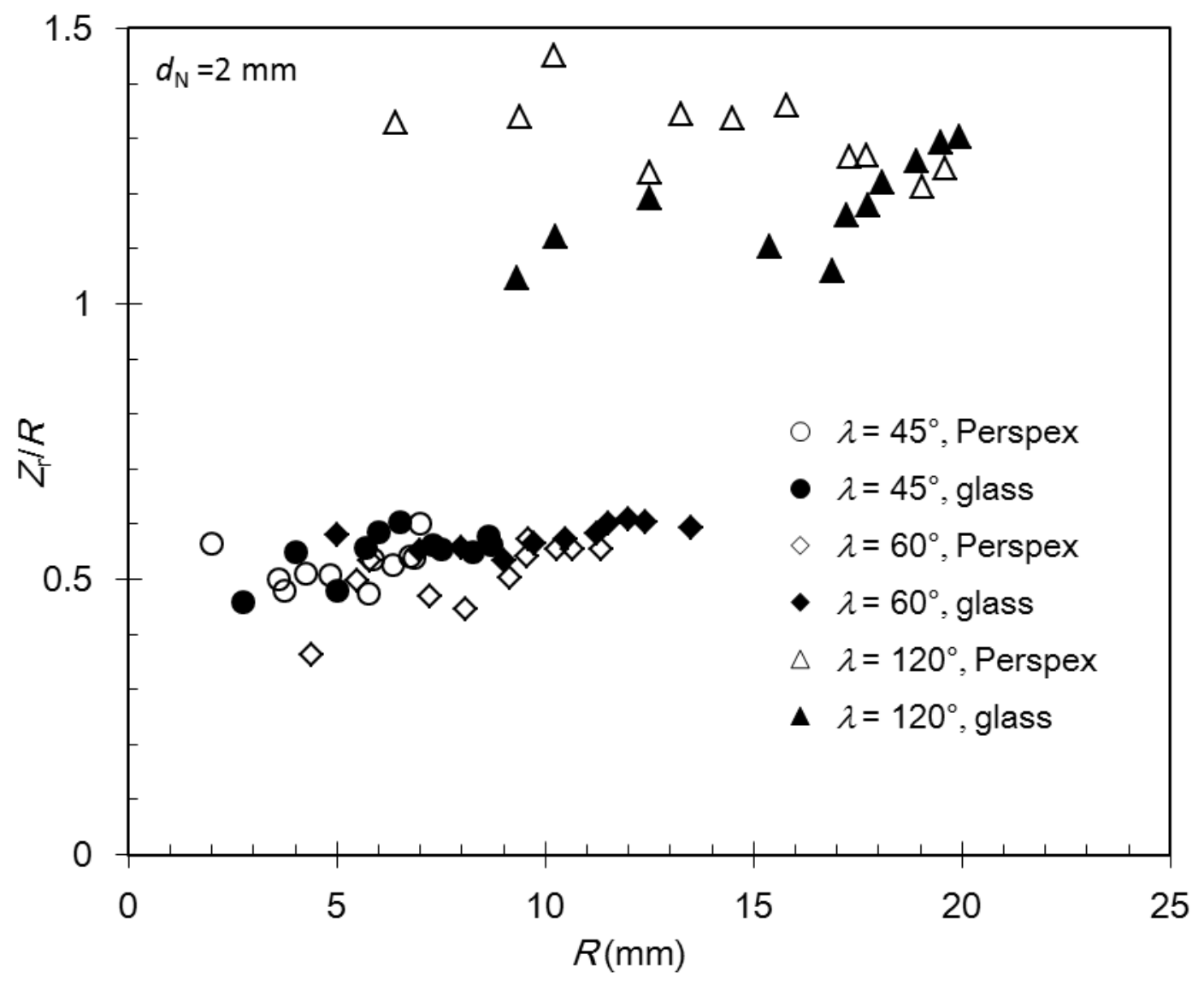

Figure A1. Data in Figure 3, replotted as $Z_{\mathrm{r}} / R$. The $x$ axis represents the mass flow rate, as $R$ increases monatonically with $\dot{m}$. For $\lambda=90^{\circ}, Z_{\mathrm{r}} / R \sim 1$. 